\title{
Storm-Track Shifts under Climate Change: Toward a Mechanistic Understanding Using Baroclinic Mean Available Potential Energy
}

\author{
Cheikh Mbengue \\ University of Oxford, Oxford, United Kingdom \\ TAPIO SCHNEIDER \\ California Institute of Technology, Pasadena, California, and ETH Zürich, Zurich, Switzerland
}

(Manuscript received 4 September 2015, in final form 23 September 2016)

\begin{abstract}
Zonal-mean storm-track shifts in response to perturbations in climate occur even in idealized simulations of dry atmospheres with axisymmetric forcing. Nonetheless, a generally accepted theory of the mechanisms controlling the storm-track shifts is still lacking. Here, mean available potential energy (MAPE), a general measure of baroclinicity that is proportional to the square of the Eady growth rate, is used to understand storm-track shifts. It is demonstrated that, in dry atmospheres, the eddy kinetic energy (EKE) in a storm track is linearly related to the mean available potential energy, relative to a local reference state, and that maxima of the two are generally collocated in latitude. Changes in MAPE with climate are then decomposed into components. It is shown that in simulations of dry atmospheres, changes in the latitude of maximum MAPE are dominated by changes in near-surface meridional temperature gradients. By contrast, changes in the magnitude of MAPE are primarily determined by changes in static stability and in the depth of the troposphere. A theory of storm-track shifts may build upon these findings and primarily needs to explain changes in near-surface meridional temperature gradients. The terminus of the Hadley circulation often shifts in tandem with storm tracks and is hypothesized to play an important role in triggering the storm-track shifts seen in this idealized dry context, especially in simulations where increases only in the convective static stability in the deep tropics suffice to shift storm tracks poleward.
\end{abstract}

\section{Introduction}

Midlatitude storm tracks respond in various ways to perturbations in the climate system. For example, the frequency and intensity of the cyclones and anticyclones making up the storm tracks can change (Geng and Sugi 2003; O'Gorman 2010; Chang 2013), and the latitudinal position of storm tracks can shift. The mechanisms controlling storm-track shifts with changes in climate are of particular interest, since a hierarchy of models shows a robust poleward shift as the climate warms (Fyfe 2003; Yin 2005; Bengtsson et al. 2006; Tsushima et al. 2006; Schneider et al. 2010; Swart and Fyfe 2012; Barnes and Polvani 2013; Mbengue and Schneider 2013, hereafter MS13). Indeed, although several theories have

Corresponding author address: Cheikh Mbengue, Atmospheric, Oceanic, and Planetary Physics, University of Oxford, Sherrington Road, Oxford OX1 3PU, United Kingdom.

E-mail: c.mbengue@wolfson.oxon.org been suggested (Kushner and Polvani 2004; Yin 2005; Chen and Held 2007; Lorenz and DeWeaver 2007; Chen et al. 2008; Lu et al. 2010; Butler et al. 2010; Kidston et al. 2010; Riviere 2011; Butler et al. 2011; Lorenz 2014), a generally accepted one remains elusive. In this study, we build upon MS13, in which an idealized dry general circulation model (GCM) was used to isolate quantities believed to be important drivers of storm-track responses to changes in climate. We continue to focus on dry and statistically axisymmetric atmospheres as a stepping stone toward the development of theories for moist atmospheres with zonal asymmetries, in which storm-track shifts under climate change may be more complex (e.g., Simpson et al. 2014; Shaw and Voigt 2015).

Using simulations as in MS13, we employ the concept of baroclinic mean available potential energy (MAPE) to explore and help explain the storm-track shifts seen in this idealized dry context. Differential large-scale radiative forcing generates MAPE, which midlatitude eddies convert into eddy available potential energy 
(EAPE) and eddy kinetic energy (EKE), primarily through baroclinic instability (Charney 1947; Eady 1949; Lorenz 1955; Phillips 1956; Orlanski and Katzfey 1991; Chang et al. 2002). Thus, there is a physical and wellestablished link between MAPE and eddy energies. Moreover, prior studies have shown that bulk measures of MAPE and EKE scale linearly with each other when averaged over a baroclinic zone (Schneider and Walker 2006, 2008; O'Gorman and Schneider 2008a; O'Gorman 2010). This linear scaling allows a simple relationship for EKE, a turbulent quantity, to be obtained in terms of MAPE, a mean-flow quantity. The scaling amounts to a turbulence closure and can be used in simple predictive models. We extend this work and test the idea that zonal and temporal averages of MAPE and of local near-surface EKE also scale linearly with each other along the storm tracks and that their maxima remain approximately collocated in latitude as the storm tracks shift. This extension suggests that changes in the position of the MAPE maximum help determine the changes in the position of the EKE maximum or the position of storm tracks.

MS13's simulations show tandem shifts of the Hadley cell terminus and the storm tracks, in agreement with the results of Kang and Polvani (2011) and Ceppi and Hartmann (2013). Indeed, Hadley cell expansion under global warming is another robust response of models and observations ( $\mathrm{Hu}$ and $\mathrm{Fu} 2007$; Seidel and Randel 2007; Lu et al. 2007; Seidel et al. 2008; Korty and Schneider 2008; Adam et al. 2014; Levine and Schneider 2015), although the Hadley circulation contracts under warming that is confined to the tropics, such as during El Niño (Seager et al. 2003; Tandon et al. 2013; Adam et al. 2014). This tandem expansion of the Hadley circulation, coupled to MS13's result that changes in the convective static stability only in the deep tropics suffice to lead to shifts in the midlatitude storm tracks, yields the hypothesis that shifts in the Hadley cell terminus can drive shifts in storm-track position.

Section 2 gives a brief overview of the methods and simulations used in this study, explaining how we identify storm tracks and how we use MAPE to understand the storm-track response to climate changes. Section 3 discusses the simulation results, and section 4 analyzes them in terms of MAPE changes. Section 5 summarizes our key findings.

\section{Methods and simulations}

\section{a. Dry idealized general circulation model}

We build on the work of MS13 and use a dry idealized GCM. The model contains no hydrological cycle or topography and thus allows us to test theories of storm tracks in an environment in which changes in mean temperature are decoupled from changes in static stability. Otherwise, changes in mean temperature are usually coupled to changes in static stability through moist dynamics and latent heat release (Xu and Emanuel 1989; Emanuel 2007; Schneider and O'Gorman 2008). This idealized dry GCM, despite its simplicity, not only captures many salient features of the observed general circulation, but also many of the observed responses to warming, including a poleward shift of storm tracks (Bender et al.2012), a rise in the height of the tropopause (Santer et al. 2003), and an expansion of the Hadley circulation (Hu and Fu 2007; Adam et al. 2014).

The dry idealized GCM is set up and forced as in MS13. We use the simulation output from MS13 supplemented by additional simulations with different pole-equator temperature contrasts (see Table 1). A detailed description of the model can be found in Schneider (2004), Schneider and Walker (2006), and MS13. Radiative and surface fluxes in the model are parameterized using Newtonian relaxation toward a radiative-equilibrium profile. Example climates produced by this model are described in MS13. The horizontal resolution of the model in all simulations we discuss (except for some simulations in Fig. 5) is T85, which corresponds to about $1.4^{\circ}$ resolution of the transform grid (see Table 1). The vertical discretization consists of 30 sigma levels in all simulations. The higherresolution T127 simulations are run for 400 days, while all other simulations are run for at least $3 \mathrm{yr}$. Averages of flow statistics are accumulated over 720 days, discarding a spinup period.

A quasi-equilibrium dry convection scheme relaxes temperatures in an atmospheric column to a specified constant lapse rate $\Gamma_{\text {conv }}=\gamma \Gamma_{d}$. If a parcel raised from the surface has convective available potential energy relative to the convective lapse rate $\Gamma_{d}$, its convective available potential energy is relaxed to zero over a time scale $\tau_{\text {conv }}$, which is $4 \mathrm{~h}$ in this study. Here, $\gamma$ is a rescaling parameter, which controls the convective stability (increasing $\gamma$, where $0<\gamma \leq 1$ implies decreasing convective stability).

Within a planetary boundary layer of fixed height $(\sigma=0.84)$, there is vertical diffusion of momentum and dry static energy $M=c_{p} T+g z$, and quadratic drag models boundary layer friction. In the remainder of the atmosphere, horizontal hyperdiffusion $\left(\nabla^{8}\right)$ acts at the smallest resolved scales on a time scale of about $12 \mathrm{~h}$.

Although similar GCMs have been used in several studies on storm tracks (Kushner and Polvani 2004; Chen and Held 2007; Butler et al. 2010), in this study, as in MS13, the GCM is forced in a unique way. We separate the effect of convective lapse-rate changes that are 
TABLE 1. Parameters for the five classes of simulations conducted in this study. There are 376 simulations in total. The increment by which each parameter is varied is shown in parentheses. The parameter values delimited by slashes indicate simulations conducted at various fixed values of a secondary parameter.

\begin{tabular}{|c|c|c|c|c|}
\hline $\begin{array}{c}\text { South pole } \\
\text { temperature }(\mathrm{K})\end{array}$ & $\begin{array}{l}\text { Tropical convective } \\
\text { lapse rate } \gamma_{e}\end{array}$ & $\begin{array}{l}\text { Extratropical convective } \\
\text { lapse rate } \gamma_{x}\end{array}$ & $\begin{array}{l}\text { Pole-equator thermal } \\
\text { contrast }(\mathrm{K})\end{array}$ & $\begin{array}{c}\text { Spectral } \\
\text { truncation }\end{array}$ \\
\hline \multicolumn{5}{|c|}{ Variations of mean temperature $^{\mathrm{a}}$} \\
\hline $190-320(10)$ & 0.60 & 1.00 & $60 / 120$ & $\mathrm{~T} 42$ \\
\hline$\vdots$ & $0.70 / 1.00$ & $0.70 / 1.00$ & 120 & $\vdots$ \\
\hline $190-285(05)$ & & $\vdots$ & $\vdots$ & $\mathrm{T} 85$ \\
\hline $210-320(10)$ & 0.70 & $\vdots$ & $60 / 120$ & $\vdots$ \\
\hline $180-210(30)$ & $0.70 / 1.00$ & $\vdots$ & 120 & $\mathrm{~T} 127$ \\
\hline \multicolumn{5}{|c|}{ Variations of pole-equator thermal contrast $\mathrm{t}^{\mathrm{b}}$} \\
\hline 260 & 0.60 & 1.00 & $45-195(15)$ & $\mathrm{T} 42$ \\
\hline \multicolumn{5}{|c|}{ Variations of extratropical convective lapse rate } \\
\hline$\vdots$ & $0.70 / 1.00$ & $0.66-0.99(0.03)$ & 120 & $\vdots$ \\
\hline \multicolumn{5}{|c|}{ Variations of tropical convective lapse rate } \\
\hline \multirow{4}{*}{280} & $0.65-1.00(0.05)$ & 1.00 & $60 / 120$ & $\vdots$ \\
\hline & $0.66-0.99(0.03)$ & $0.70 / 1.00$ & 120 & $\vdots$ \\
\hline & $0.60-0.98(0.02)$ & 0.98 & . & $\mathrm{T} 85$ \\
\hline & $0.70-0.90(0.05)$ & $\vdots$ & $\vdots$ & $\mathrm{T} 127$ \\
\hline \multicolumn{5}{|c|}{ Variations of global convective lapse rate } \\
\hline \multirow[t]{2}{*}{260} & & $0.65-1.00(0.05)$ & $60 / 120$ & $\mathrm{~T} 42$ \\
\hline & & $0.66-0.99(0.03)$ & 120 & $\vdots$ \\
\hline \multirow[t]{2}{*}{280} & & $0.60-0.98(0.02)$ & · & $\mathrm{T} 85$ \\
\hline & & $0.70-0.90(0.05)$ &. & $\mathrm{T} 127$ \\
\hline
\end{tabular}

${ }^{a}$ For example, the first row shows two sets of simulations; each consists of 14 simulations.

${ }^{\mathrm{b}}$ Includes two additional simulations at pole-equator thermal contrasts of 240 and $255 \mathrm{~K}$.

global from those confined to the tropics by partitioning the model domain into a deep tropical zone (latitudes $|\varphi|<10^{\circ}$, subscript $\left.e\right)$ and an extratropical zone $(|\varphi| \geq$ $10^{\circ}$, subscript $x$ ), each with its own independently varied convective lapse-rate rescaling parameter $\gamma_{e}$ and $\gamma_{x}$.

In this study, we perform most of our analysis on the simulations from MS13, but several new series of simulations are added for comparison (see Table 1). In the first set of simulations, the mean surface temperature in radiative equilibrium is varied from $\bar{T}_{s}^{e}=270$ to $365 \mathrm{~K}$ in increments of $5 \mathrm{~K}$. This set of simulations is run with convective lapse rates that are either globally constant $\left(\gamma=\gamma_{x}=\gamma_{e}\right)$ or that assume different values near the equator $\left(\gamma_{e}\right)$ and away from it $\left(\gamma_{x}\right)$. In the second set of simulations, the mean radiative-equilibrium surface temperature remains fixed $\left(\bar{T}_{s}^{e}=340 \mathrm{~K}\right)$ but the convective lapse rate is varied by changing the rescaling parameter $\gamma$ in increments of about 0.02 , either globally or only near the equator while keeping $\gamma_{x}=1$ fixed (see MS13 for further details of the simulations).

\section{b. Midlatitude storm tracks}

To theorize about midlatitude storm tracks requires a way of identifying them. Several proxies have been used in the literature to reason about storm tracks; see Chang et al. (2002) for a review. For example, bandpass-filtered eddy fields represent a good storm-track proxy when taking an Eulerian view of storm tracks (Blackmon 1976; Blackmon et al. 1977; Hoskins and Valdes 1990) and are useful for investigating the storm-track climatology and its response to climate change (Yin 2005; Chang et al. 2013). Synoptic feature tracking, a Lagrangian perspective, also continues to be used (Murray and Simmonds 1991; Hoskins and Hodges 2002).

In this study, we are interested in the storm-track response on climatological time scales and identify storm tracks with the maxima of the zonal and temporal averages of EKE. Indeed, storm intensity has long been measured by the kinetic energy (Lorenz 1955). EKE is given by

$$
\operatorname{EKE}(\varphi)=\frac{p_{s}}{2 g} \int_{0}^{1}\left(\overline{u^{\prime 2}}+\overline{v^{\prime 2}}\right) d \sigma,
$$

where $p_{s}$ is surface pressure, $\sigma=p / p_{s}$ is the vertical coordinate, and $\overline{(\cdot)}$ represents an arithmetic mean along a latitude circle and in time and $(\cdot)^{\prime}$ deviations therefrom. Thus, we identify storm tracks from kinetic energy averages over many synoptic systems over many years. We have crosschecked our results with alternative storm-track proxies, such as zonal-mean surface wind and meridional and vertical eddy heat fluxes, and the results are similar. 


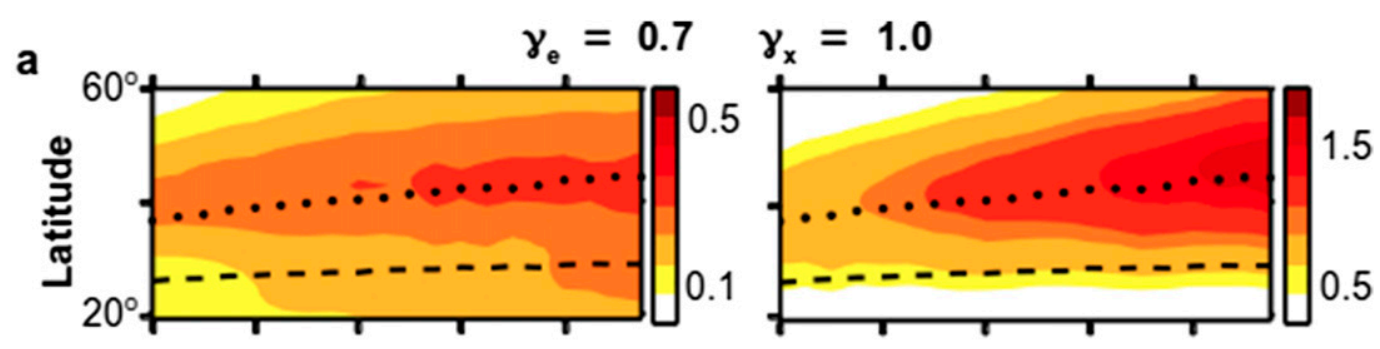

b

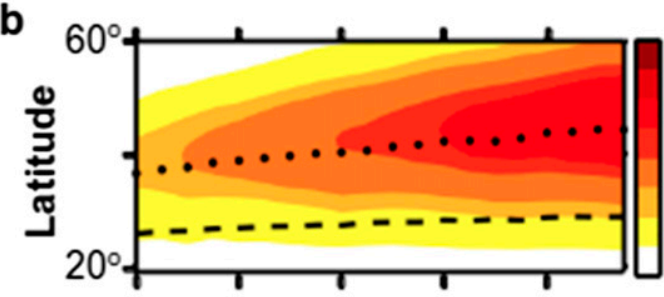

C

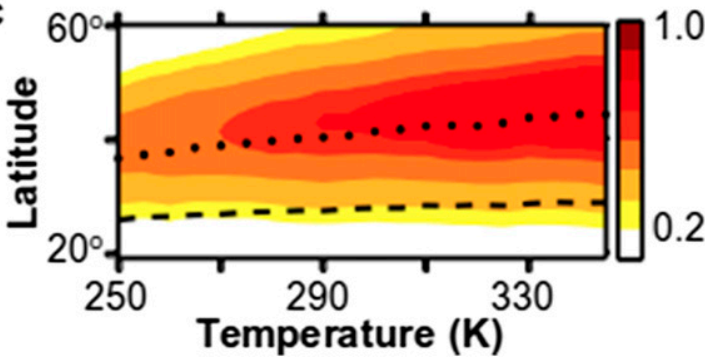

2.5
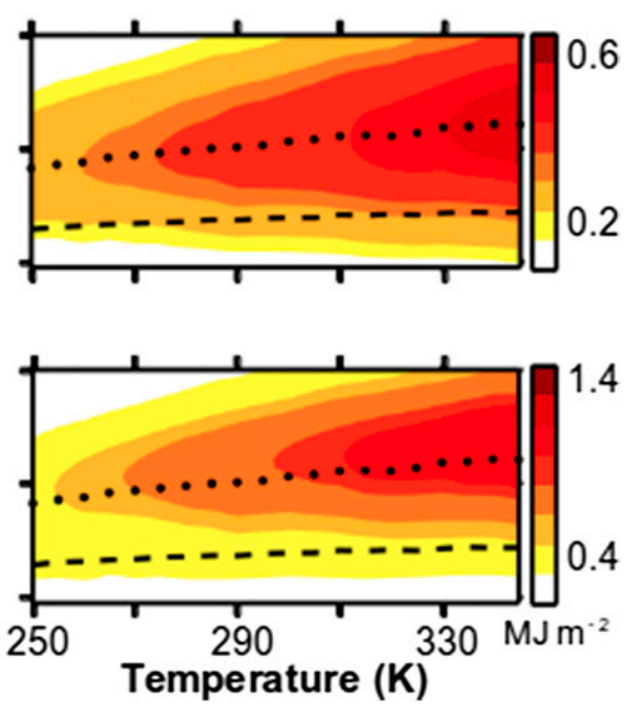

FIG. 1. Eddy kinetic energy response to mean radiative-equilibrium temperature variations, shown for simulations in which the tropics are more stable than the extratropics. (a) (left) Baroclinic and (right) barotropic EKE. (b) (left) Tropospheric EKE, integrated from the surface to the tropopause, and (right) near-surface EKE, integrated from the surface to $\sigma=0.6$. (c) (left) Midtropospheric EKE, integrated from $\sigma=0.6$ to 0.4 , and (right) upper-tropospheric EKE, integrated from $\sigma=0.4$ to 0.2 . The following convention is used throughout the figures in this paper: the black dots represent the storm tracks identified as the near-surface EKE maximum; the black dashed line represents the terminus of the Hadley circulation. Baroclinic EKE is computed using the difference between the total velocity variance and the barotropic velocity variance.

Although storm tracks are three-dimensional structures within the general circulation, we neglect asymmetries within a latitude circle. Zonal asymmetries are most prominent in Earth's Northern Hemisphere; they help to localize storm tracks there. MS13 used barotropic EKE, given by

$$
\operatorname{EKE}_{\mathrm{bt}}(\varphi)=\frac{p_{s}}{2 g}\left[\overline{\left(\int_{0}^{1} u^{\prime} d \sigma\right)^{2}}+\overline{\left(\int_{0}^{1} v^{\prime} d \sigma\right)^{2}}\right],
$$

and demonstrated poleward storm-track shifts with increasing mean radiative-equilibrium temperature or convective static stability. However, in Earth-like configurations, EKE generally attains a maximum in the upper troposphere (Ait-Chaalal and Schneider 2015), and stratospheric dynamics could influence barotropic measures of EKE. Hence, changes in the structure of barotropic EKE with climate could be biased toward upper-tropospheric and, possibly, stratospheric changes, resulting in divergences from the near-surface kinetic energy response, in which we are primarily interested. Therefore, here we use near-surface EKE to identify storm tracks, integrated from the surface to $\sigma=0.6$.

Figure 1 shows the response of several measures of EKE to mean radiative-equilibrium temperature variations for simulations in which the convective static stability is greater in the tropics than in the extratropics. For this set of simulations, all measures of EKE exhibit the same response. Thus, in this case, using barotropic EKE to identify storm tracks gives similar results as using near-surface EKE. Note that in all figures in this paper, the black dots represent the storm tracks, identified as maxima of near-surface EKE, and the dashed black line represents the latitude of the terminus of the Hadley circulation, identified as the zero crossing of the 


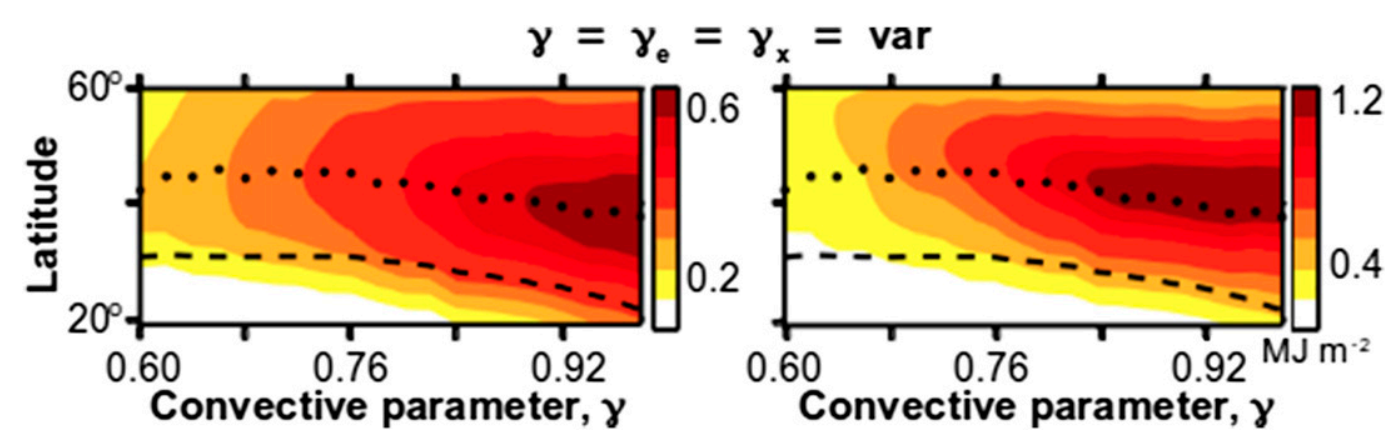

FIG. 2. Eddy kinetic energy response shown for simulations in which the global convective stability varies. (left) Near-surface EKE and (right) upper-tropospheric EKE.

meridional streamfunction at the sigma level where it attains its extremum.

The most notable examples of when barotropic and near-surface EKE give different storm-track responses come from simulations in which the convective static stability is varied globally. As the global convective static stability increases, the upper-tropospheric EKE maximum continues its poleward migration, while the mid- and lower-tropospheric EKE maxima and the Hadley cell terminus at some point cease their poleward migration (Fig. 2). This vertical tilting of the storm tracks as the climate changes is not well captured using barotropic EKE, which mirrors the upper-tropospheric response. Since we are particularly interested in how lower-tropospheric EKE responds to changes in climate, we use near-surface EKE to identify storm tracks and employ it to help build a theory of the storm-track response to perturbations in climate.

\section{c. Baroclinic MAPE}

Available potential energy, as introduced by Lorenz (1955), refers to the energy excess over a minimum potential energy state obtained by an adiabatic redistribution of mass along isentropes [see Dutton and Johnson (1967) and Tailleux (2013) for reviews]. It describes the maximum amount of potential energy available for conversion into kinetic energy and depends on the variance of pressure on isentropic surfaces. It can be approximated by the potential temperature variance on isobaric surfaces by

$$
\mathrm{APE}=\frac{1}{2} \kappa \Gamma_{d}^{-1} p_{0}^{-\kappa} \int_{0}^{p_{s}}\langle p\rangle^{\kappa-1}\left\langle-\partial_{p} \theta\right\rangle^{-1}\left\langle\theta^{* 2}\right\rangle d p
$$

where $p_{0}$ is a reference pressure, and $\langle\cdot\rangle$ represents a global mean on an isobaric surface and $(\cdot)^{*}$ deviations therefrom (Lorenz 1955). APE can be partitioned into MAPE and EAPE by decomposing the global potential temperature variance into components associated with deviations of the zonal mean from the global mean and with local and temporal deviations from the zonal mean, giving

$$
\text { MAPE }=\frac{1}{2} \kappa \Gamma_{d}^{-1} p_{0}^{-\kappa} \int_{0}^{p_{s}}\langle p\rangle^{\kappa-1}\left\langle-\partial_{p} \theta\right\rangle^{-1}\left\langle[\bar{\theta}-\langle\theta\rangle]^{2}\right\rangle d p
$$

and

$$
\mathrm{EAPE}=\frac{1}{2} \kappa \Gamma_{d}^{-1} p_{0}^{-\kappa} \int_{0}^{p_{s}}\langle p\rangle^{\kappa-1}\left\langle-\partial_{p} \theta\right\rangle^{-1}\left\langle\overline{\theta^{\prime 2}}\right\rangle d p .
$$

See Lorenz (1955) and Phillips (1956) for a discussion of this decomposition and its importance for the energy cycle of Earth's atmosphere. In Earth's atmosphere, MAPE is generated through the differential solar heating and longwave cooling of the planet. Midlatitude eddies convert MAPE to EAPE and EKE through baroclinic conversion, primarily in the strongly baroclinic regions in the storm tracks (e.g., Lorenz 1955; Orlanski and Katzfey 1991; Chang et al. 2002).

APE is an attractive quantity; however, some controversy surrounds determining the appropriate reference state-a hypothetical minimum energy state reachable through a succession of physical processes. As has been pointed out by Dutton and Johnson (1967) and Smith (1969), among others, the reference state is important because it provides information about the state to which the atmosphere relaxes. We follow the definition of APE of Lorenz (1955), which gives an upper bound on APE, with a reference state that is reached by adiabatic rearrangements of air masses, disregarding constraints-for example, from the angular momentum balance the airmass rearrangements would have to satisfy in reality. Lorenz's APE is useful for studying the maintenance of the general circulation against dissipation (Lorenz 1955; Dutton and Johnson 1967; Johnson 1970). Here we focus on MAPE in a limited region, like many authors before us (Smith 1969; Smith and Horn 1969; Johnson 1970; Smith et al. 1977; Schneider and Walker 2008; Chang 2013; 
Yuval and Kaspi 2016), because eddies can tap a MAPE reservoir only within their length scales. That is, eddies tend to relax MAPE locally toward zero in a baroclinic zone. Therefore, we use a local reference state (Smith and Horn 1969; Johnson 1970; Smith et al. 1977) instead of a global reference state (Smith 1969; Kucharski 1997; Kucharski and Thorpe 2000).

The local MAPE used in this paper is a simple extension of Lorenz's MAPE and is closely related to the local MAPE discussed by Smith and Horn (1969) and Johnson (1970). The local reference state used here is a local analog of Lorenz's reference state - that is, a state with vanishing horizontal potential temperature gradients and statically stable stratification within a latitude band. Therefore, we imagine baroclinic eddies that, in the mean, mix entropy over a length scale $L_{z}$-the width of the baroclinic zone. We define the mean potential temperature and departures therefrom over the baroclinic zone, as opposed to globally (cf. Kucharski 1997; Kucharski and Thorpe 2000). Thus, we use a baroclinic MAPE (Smith and Horn 1969; Johnson 1970; Smith et al. 1977). To obtain the local MAPE, one could convolve the local quantities in (4) with a filter function, using a window size corresponding to the width of the baroclinic zone. However, we use the approximate MAPE first derived by Schneider (1984) and Schneider and Walker (2008) and apply it locally,

$$
\operatorname{MAPE}(\varphi) \approx \frac{\kappa}{24 p_{0} \Gamma_{d}}\left(-\partial_{p} \bar{\theta}\right)_{s}^{-1} \Delta p\left(L_{z} \partial_{y} \bar{\theta}_{s}\right)^{2} .
$$

Here, the subscript $s$ indicates near-surface quantities, and $\Delta p=\bar{p}_{s}-\bar{p}_{t}$ is the mean pressure difference between the surface $\left(p_{s}\right)$ and the tropopause $\left(p_{t}\right)$. In this study, the tropopause is identified as the first level with pressure below $500 \mathrm{hPa}$ at which the temperature lapse rate reaches $2 \mathrm{~K} \mathrm{~km}^{-1}$ (WMO criterion). We use a fixed width $L_{z}$ of the baroclinic zone, corresponding to a span of $30^{\circ}$ in latitude; using a variable baroclinic zone width increases the complexity of the analysis without appreciably changing the results. The local MAPE (6) is obtained from Lorenz's MAPE by expanding potential temperature variations about the center of the baroclinic zone. See appendix A in Schneider and Walker (2006) for further details and for a demonstration of the accuracy of this approximation. We use the local MAPE (6) because it is the most straightforward local approximation of (4) with direct applicability to baroclinic eddies and extratropical dynamics.

The local MAPE (6) highlights important quantities for reasoning about changes in APE: the pressure depth of the troposphere $\Delta p$, the meridional temperature gradient $\partial_{y} \bar{\theta}$ (or, through the thermal wind relation, the vertical shear $\partial_{z} \bar{u}$ ), and the static stability, $-\partial_{p} \bar{\theta}$. The latter two of these quantities appear in other important quantities measuring baroclinicity: for example, the Eady growth rate, $0.3 f \partial_{z} u / N$, which is proportional to (MAPE) ${ }^{1 / 2}$ (Lindzen and Farrel 1980; Hoskins and Valdes 1990), and the isentropic slope $I=\partial_{y} \bar{\theta} / \partial_{p} \bar{\theta}$ (Held and Schneider 1999; Schneider and Walker 2006; Butler et al. 2011; Thompson and Birner 2012; Papritz and Spengler 2015). The local MAPE (6) has the potential to be a unifying general measure of baroclinicity. For moist circulations, it may need to be generalized by taking temperature gradients in the upper troposphere into account (O'Gorman and Schneider 2008b) or the effects of latent heat release on the effective static stability experienced by eddies (O'Gorman 2011); however, in our dry simulations, the simplified version (6) based on near-surface temperatures appears adequate (Walker and Schneider 2006).

In addition to being a possible unifying quantity, MAPE is useful because it is a mean-flow quantity, from which a mechanistic link can be traced to eddy energies. Given that MAPE and EKE are largely related through baroclinic conversion, one can hypothesize that some scaling relationship exists between the two, and it may be possible to use such a scaling to further understand stormtrack dynamics. Indeed, prior studies have shown linear scaling relations between bulk measures of MAPE and of EKE (Schneider and Walker 2006, 2008; O'Gorman and Schneider 2008b; O'Gorman 2010). Such scaling relations were shown to hold over four orders of magnitude of eddy energies and over different dynamical flow regimes. We extend this work and investigate the relationship between local measures of MAPE and near-surface EKE along the storm tracks. If they scale with each other and if their maxima are collocated, it becomes possible to make inferences about changes in zonal-mean storm-track position using local MAPE.

Nonetheless, it is worth noting that the local MAPE used here and its associated energy conversions must be considered as local contributions to their respective global budgets (Johnson 1970). It is not the same as APE density (Tailleux 2013), whose local contributions, in contrast to the local MAPE used here, sum to the global APE. Because MAPE as used here is proportional to the square of the Eady growth rate, and because MAPE attains its maximum in the region of maximum storminess, whereas the APE density attains a minimum there, we consider MAPE to be better suited to studies of macroturbulence.

\section{Simulation results}

\section{a. Storm-track response}

Zonal-mean surface westerlies and vertically integrated (between $\sigma=0.8$ and $\sigma=0.2$ ) eddy meridional 

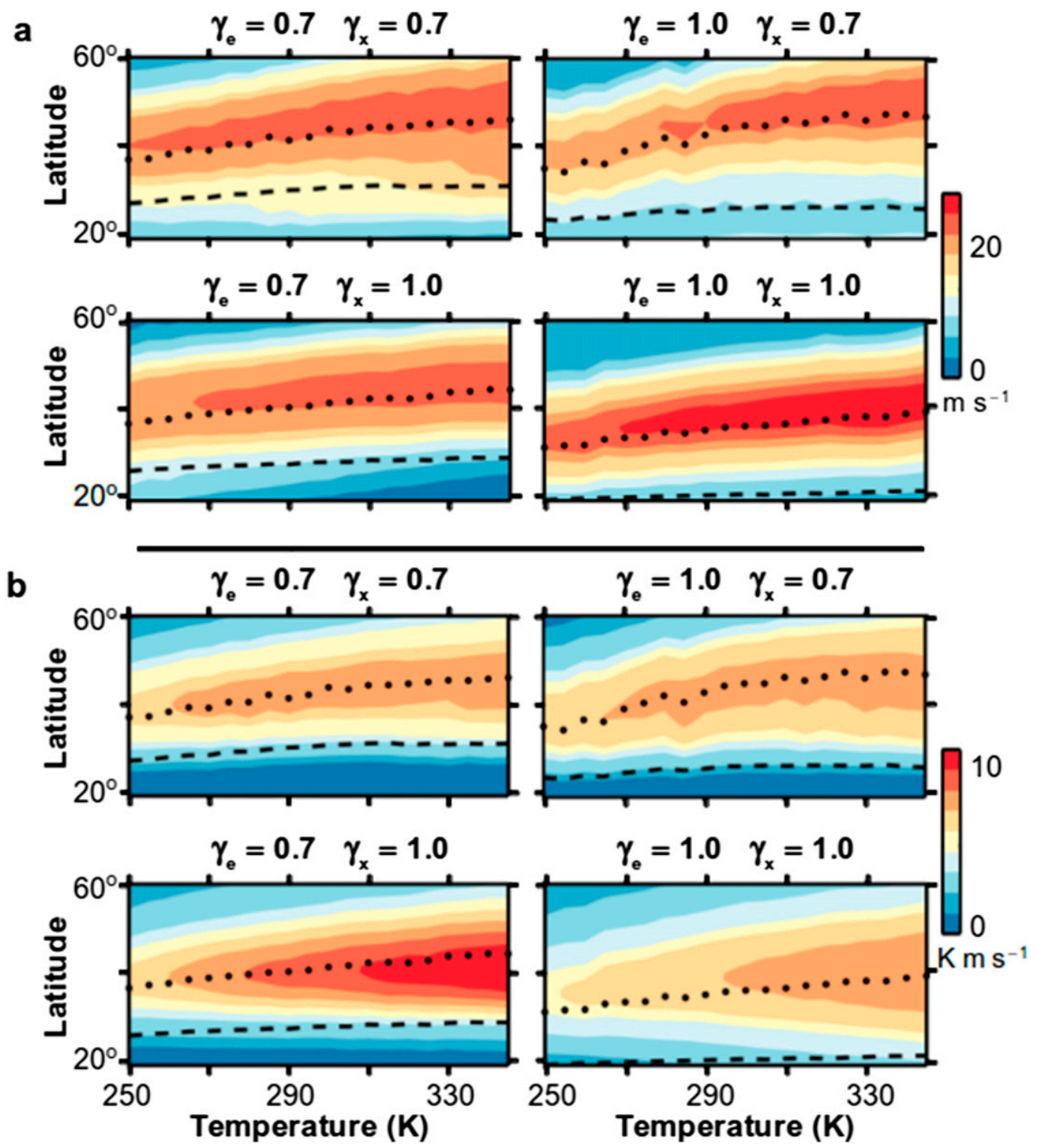

FIG. 3. (a) Near-surface zonal-mean zonal wind $\bar{u}$ and (b) vertically integrated (from $\sigma=0.8$ to 0.2 ) meridional eddy heat flux $\overline{v^{\prime} \theta^{\prime}}$ for simulations in which the mean radiative-equilibrium temperature is varied. In (a) and (b), (top left) $\gamma_{e}=\gamma_{x}=0.7$, (top right) $\gamma_{e}=1.0$ and $\gamma_{x}=0.7$, (bottom left) $\gamma_{e}=0.7$ and $\gamma_{x}=1.0$, and (bottom right) $\gamma_{e}=$ 1.0 and $\gamma_{x}=1.0$. There is general agreement in the response of different storm-track proxies to mean radiativeequilibrium temperature variations: they all shift poleward as the climate warms and generally do so in tandem with the terminus of the Hadley circulation.

heat fluxes both shift poleward as the mean radiativeequilibrium temperature is increased (Fig. 3). A poleward shift of the maximum in surface westerlies implies a concomitant poleward shift of maximum vertically integrated meridional eddy momentum flux convergence $\left(-\partial_{y} \overline{u^{\prime} v^{\prime}}\right)$ within the troposphere. The maximum of the near-surface meridional (potential) temperature gradient $\left(\partial_{y} \bar{\theta}_{s}\right)$ also shifts poleward. There is only a small increase in the maximum strength of the surface westerlies along the storm tracks. Instead, a greater change in surface westerlies occurs at a fixed latitude. Latitudes poleward of the storm tracks (within the surface westerlies) see increased westerly wind speeds with warming, while latitudes equatorward of the storm tracks see a decrease. The largest shift of surface westerlies occurs when the convective static stability in the extratropics is greater than in the deep tropics (Fig. 3a, top right). 
a

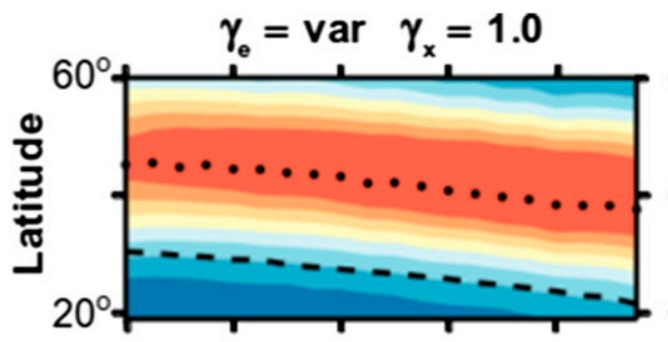

b

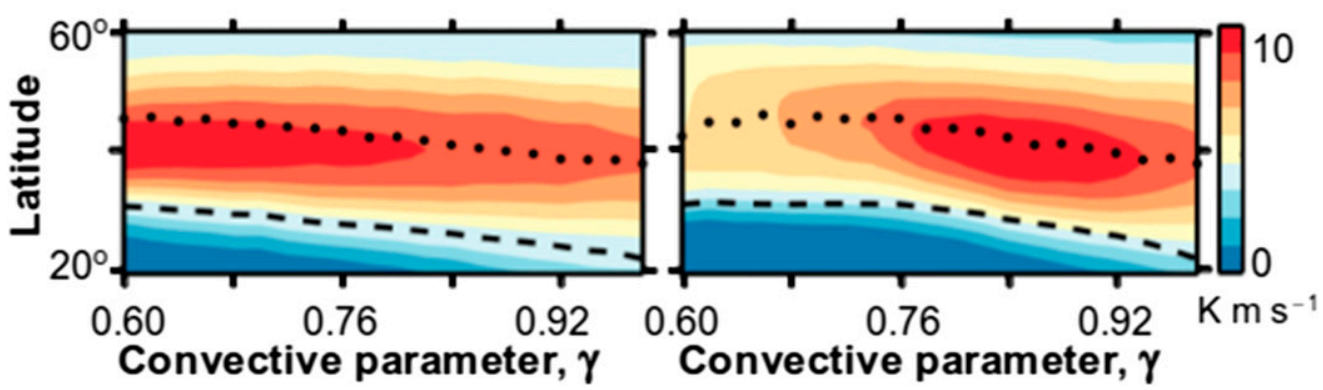

FIG. 4. (a) Near-surface zonal-mean zonal wind $\bar{u}$ and (b) vertically integrated meridional eddy heat flux $\overline{v^{\prime} \theta^{\prime}}$ for simulations in which the convective static stability is varied in (left) the deep tropics and (right) globally. In (a) and (b), (left) $\gamma_{e}=$ var and $\gamma_{x}=1.0$ and (right) $\gamma=\gamma_{e}=\gamma_{x}=$ var. There is agreement in the response of different stormtrack proxies to increases in the convective static stability (deep tropical or global): they all shift poleward and generally in tandem with the terminus of the Hadley circulation.

If one fixes the mean radiative-equilibrium temperature and increases the convective static stability (i.e., if one decreases $\gamma$ ), the zonal-mean surface westerlies likewise shift poleward (Fig. 4a). The largest changes in the strength of the surface westerlies occur when the convective static stability is varied globally (Fig. 4a, right): the strength of the westerlies decreases as the convective static stability is increased. In these simulations, the near-surface isentropic slope, $I=\left|\partial_{y} \bar{\theta} / \partial_{p} \bar{\theta}\right|$ decreases rapidly along the storm tracks as the convective static stability increases, reducing the baroclinicity and the eddy momentum flux convergence, which drives the surface westerlies (Schneider and Walker 2008).

The maximum of the meridional eddy heat flux is generally collocated in latitude with the EKE maximum (Fig. 4b). But there are some climates in which the eddy heat flux maximum sits equatorward of the EKE maximum. As the convective static stability increases globally, the maximum temperature gradient shifts from the midlatitudes to the subtropics near the Hadley cell terminus. In climates with a strong global convective static stability, in which eddies are weak, the thermally driven subtropical jet dominates the dynamics-accounting for the broadening of surface westerlies seen in those climates (Fig. 4a, right).
All storm-track proxies shift poleward as the climate warms or as the convective static stability is increased globally or only in the deep tropics. With few exceptions, all metrics shift in tandem with the Hadley cell terminus, suggesting that the Hadley circulation may play a role in the shifts seen in these simulations (MS13).

\section{b. Relationship among eddy kinetic energies and $M A P E$}

In our simulations, bulk measures of EKE scale with bulk measures of MAPE when averaged over a baroclinic zone (within $15^{\circ}$ of the latitude of maximum eddy potential to kinetic energy conversion). These findings demonstrate that the simulations conducted in this study obey the scalings found in previous studies (Schneider and Walker 2006, 2008; O'Gorman and Schneider 2008a; O'Gorman 2010). We take this scaling result a step further and show that local MAPE scales linearly with local near-surface EKE along the storm tracks in an extended set of 376 simulations with the dry GCM (Fig. 5a). This result helps justify using MAPE, a mean-flow quantity, to draw inferences about shifts in storm tracks or EKE, a turbulent quantity. It is worth noting that the scaling between the magnitudes of MAPE and EKE does less well in simulations with weak macroturbulence, in which the static stability is strong or pole-equator thermal contrasts are weak. In these 

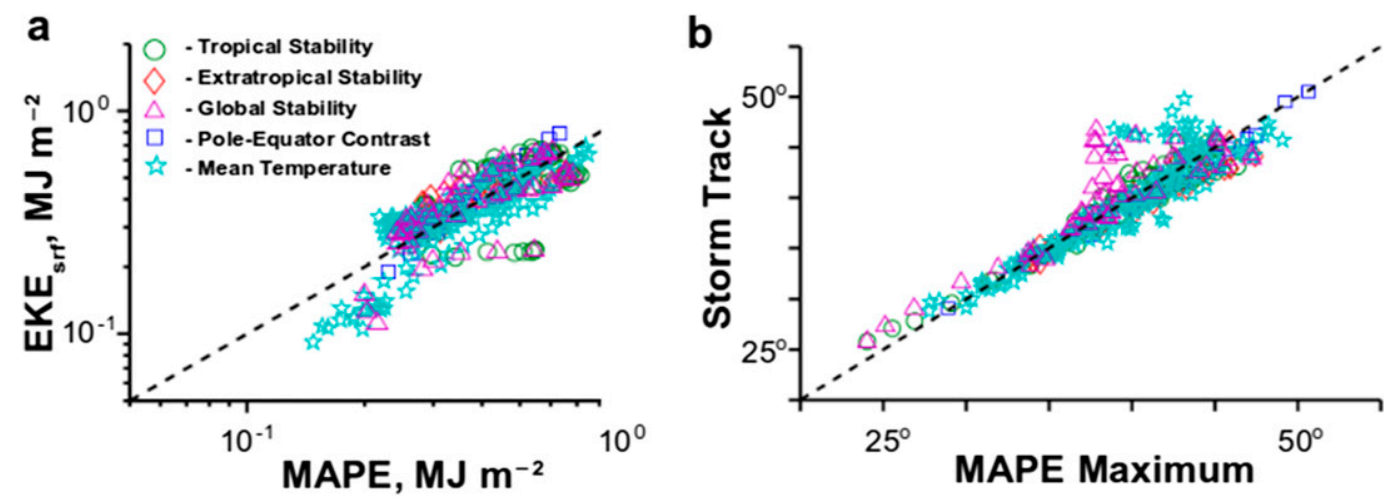

FIG. 5. (a) Relationship between local MAPE and near-surface EKE along the storm tracks, using an expanded set of 376 idealized simulations. (b) Relationship between the latitude of maximum local MAPE and the stormtrack latitude (near-surface EKE maximum). Shapes and colors of the plotting symbols indicate the simulation class. The bulk scalings demonstrated in previous studies hold in this study; they also apply locally along the midlatitude storm tracks. Furthermore, along the storm tracks, maxima of local MAPE and near-surface EKE are generally collocated.

simulations, baroclinic eddies are unable to tap into MAPE effectively (possibly also as a result of numerical resolution limitations).

MAPE along the storm tracks increases with increasing mean radiative-equilibrium temperature (Fig. 6a), albeit less so in simulations with convectively more stable extratropics (Fig. 6a, top row). In these simulations, the increase in MAPE is largely due to a decrease in midlatitude stability, supplemented by an increase in the height of the tropopause when the surface temperature increases. MAPE also increases with decreasing convective stability (Fig. 6b). In these simulations, however, an increase in the meridional temperature gradient drives the increase in MAPE. More generally, the MAPE maximum shifts poleward in tandem with the EKE maximum as the climate changes.

Importantly for our purposes, local maxima of MAPE (black circles in the figures) across climates are generally collocated in latitude with local maxima of near-surface EKE (black dots in the figures), as seen in Fig. 5b. The collocation between the MAPE and nearsurface EKE maxima seems relatively robust. In some climates, the MAPE maximum does not lie exactly at the near-surface EKE maximum; however, they generally lie within a few degrees of each other and shift in tandem.

There are some simulations in which the discrepancies are greater. Where the MAPE maximum lies equatorward of the EKE maximum, usually the MAPE maximum is at the subtropical jet, and there is a secondary midlatitude MAPE maximum near the EKE maximum (see Fig. 6a, top left). When the MAPE maximum lies poleward of the EKE maximum (not shown), macroturbulence is generally weak and the tropopause low. The high MAPE poleward of the EKE maximum is associated with low static stability and is effectively decoupled from the lower latitudes where EKE attains its maximum. Nonetheless, it generally does appear to be a useful approximation to identify the storm-track latitude with the MAPE maximum.

\section{Using MAPE to understand storm-track shifts}

Because maxima of MAPE and EKE are approximately collocated in latitude, shifts in MAPE can be used to understand shifts in storm tracks.

\section{a. MAPE decomposition}

The results so far suggest that decomposing MAPE into its component parts may yield insight into the storm-track response to perturbations in climate. Using the local MAPE (6), we decompose variations in MAPE into variations in the squared near-surface meridional (potential) temperature gradient $\left(\partial_{y} \bar{\theta}_{s}\right)^{2}$, in the near-surface inverse static stability $\left(-\partial_{p} \bar{\theta}\right)_{s}^{-1}$, and in the pressure depth of the troposphere $\Delta p$. Taking the logarithm of the local MAPE (6), where $\xi$ consolidates all constants and we assume the zonalmean static stability near the surface to be nonnegative, gives

$$
\begin{aligned}
\ln (\mathrm{MAPE}) & =\ln \frac{\xi \Delta p\left(\partial_{y} \bar{\theta}_{s}\right)^{2}}{\left(-\partial_{p} \bar{\theta}\right)_{s}}, \\
& =\ln \xi+\ln \Delta p+\ln \left(\partial_{y} \bar{\theta}_{s}\right)^{2}-\ln \left(-\partial_{p} \bar{\theta}\right)_{s} .
\end{aligned}
$$


a
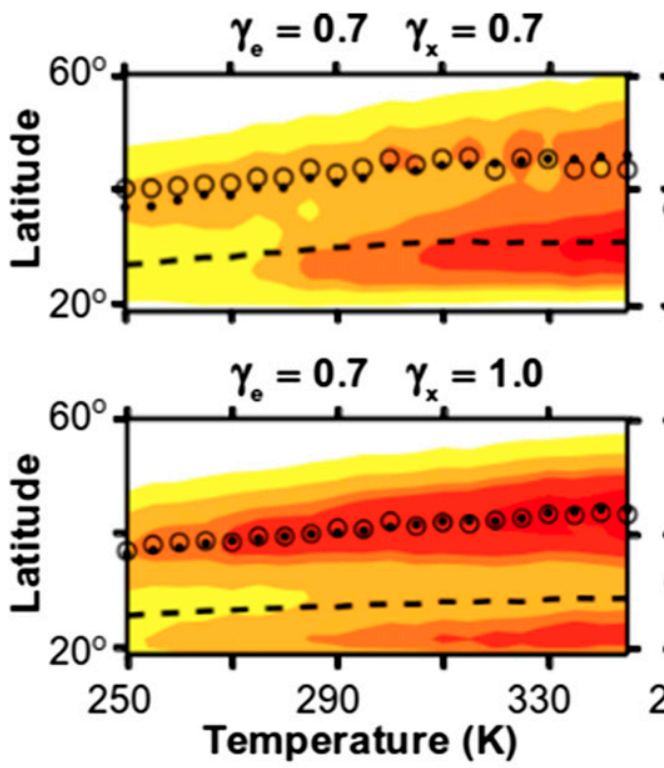
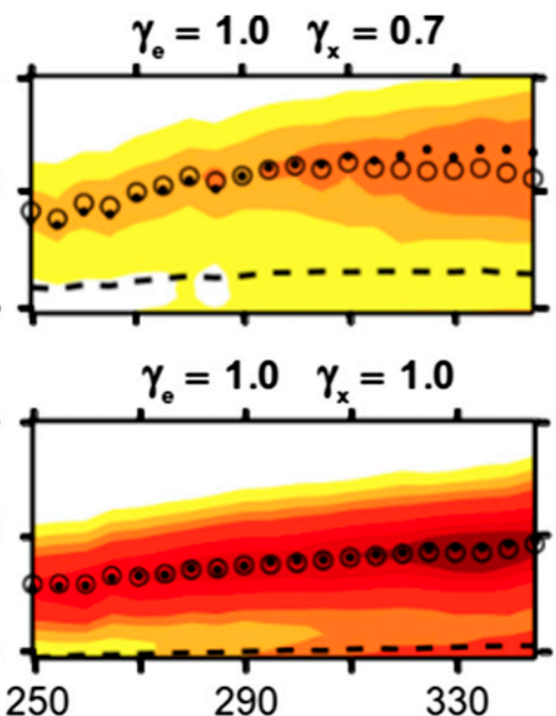

Temperature (K)

b

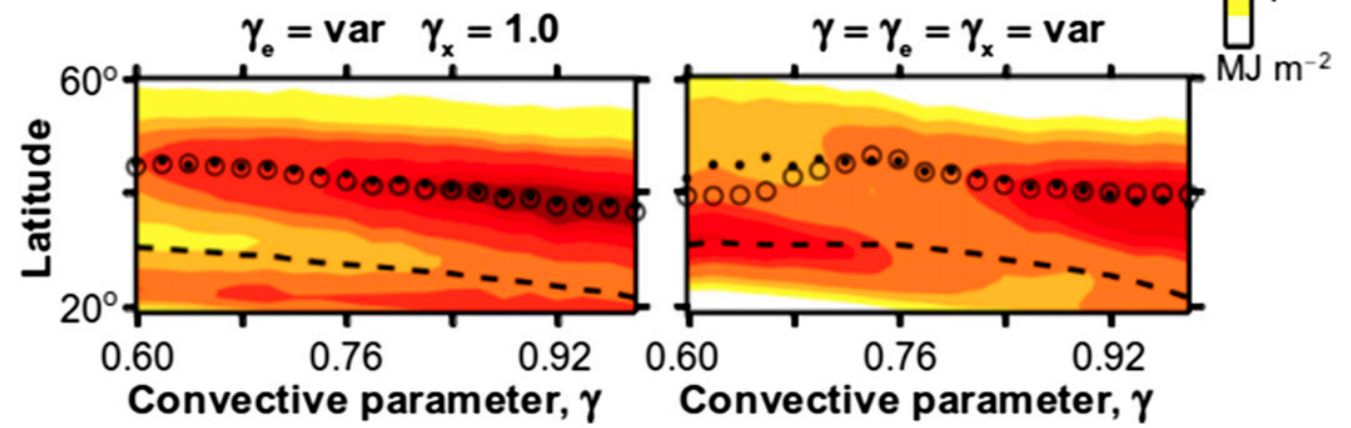

FIG. 6. Mean available potential energy for simulations in which the (a) mean radiative-equilibrium temperature and (b) convective stability are varied. In (a), (top left) $\gamma_{e}=\gamma_{x}=0.7$, (top right) $\gamma_{e}=1.0$ and $\gamma_{x}=0.7$, (bottom left) $\gamma_{e}=0.7$ and $\gamma_{x}=1.0$, and (bottom right) $\gamma_{e}=\gamma_{x}=1.0$. In (b), (left) $\gamma_{e}=$ var and $\gamma_{x}=1.0$ and (right) $\gamma=\gamma_{e}=\gamma_{x}=$ var. MAPE maxima, identified by the black open circles, are collocated with near-surface EKE maxima (storm tracks).

We normalize MAPE by a fictitious yet mathematically expedient climate: the geometric mean ${ }^{1} \overline{(\cdot)^{*}}$ of MAPE in the climate-latitude space (that is the geometric mean of the points in Fig. 6). To do this, we subtract the logarithm of the geometric mean MAPE from both sides of (7),

$$
\begin{aligned}
\ln \left(\frac{\mathrm{MAPE}}{\overline{\mathrm{MAPE}}^{*}}\right)= & \ln \xi+\ln \Delta p+\ln \left(\partial_{y} \bar{\theta}_{s}\right)^{2} \\
& -\ln \left(-\partial_{p} \bar{\theta}\right)_{s}-\ln \left(\overline{\mathrm{MAPE}}^{*}\right) .
\end{aligned}
$$

\footnotetext{
${ }^{1}$ For a set $x_{1}, \ldots, x_{M}$, the geometric mean is given by $\left(\prod_{j=1}^{M} x_{j}\right)^{1 / M}$.
}

Since the product of geometric means is the geometric mean of the product, we obtain the following exact decomposition of MAPE:

$$
\ln \left(\frac{\mathrm{MAPE}^{*}}{\overline{\mathrm{MAPE}}^{*}}\right)=\ln \left(\frac{\Delta p}{\overline{\Delta p}^{*}}\right)+\ln \frac{\left(\partial_{y} \bar{\theta}_{s}\right)^{2}}{{\overline{\left(\partial_{y} \bar{\theta}_{s}\right)^{2}}}^{*}}+\ln \frac{{\overline{\left(\partial_{p} \bar{\theta}\right)_{s}}}^{*}}{\left(\partial_{p} \bar{\theta}\right)_{s}} .
$$

The above decomposition allows us to investigate how each of the components of MAPE changes with climate. Perhaps equally important is the fact that this decomposition is exact and does not suffer from the approximate nature of truncated Taylor expansions about a reference climate. The main drawback, however, is that the reference climate is not a 
a
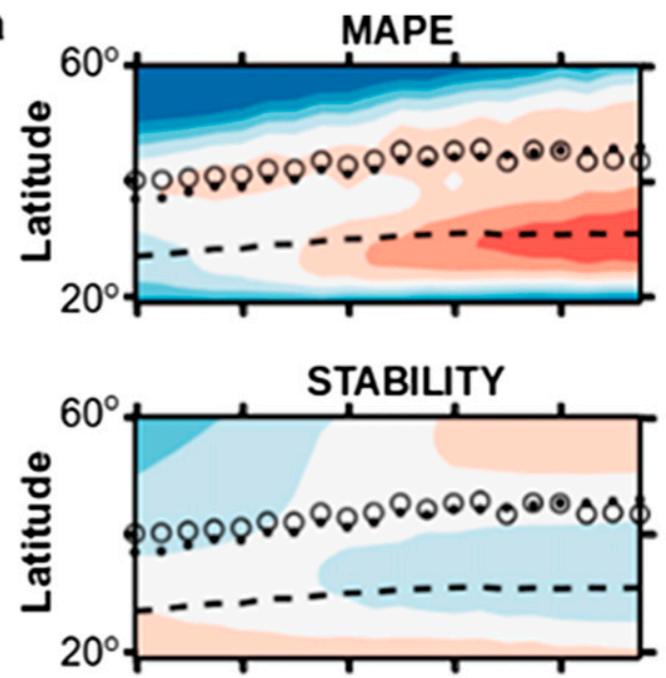

b

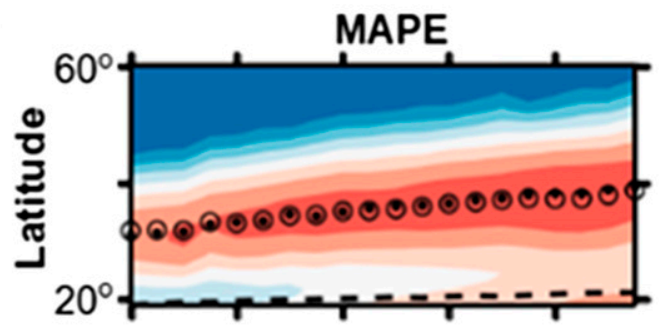

STABILITY

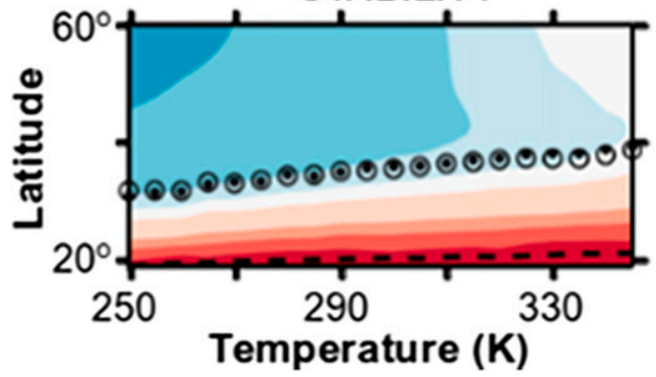

TEMPERATURE GRADIENT

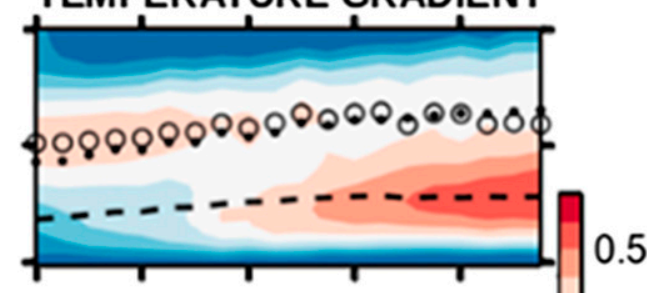

TROPOPAUSE HEIGHT

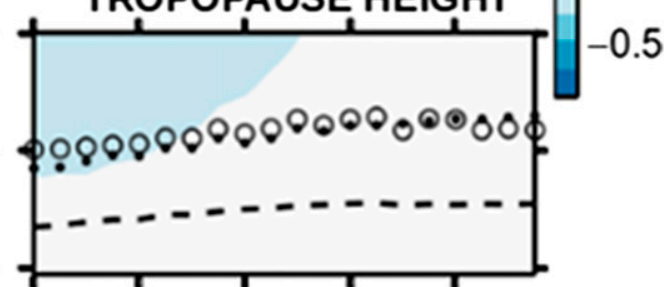

TEMPERATURE GRADIENT

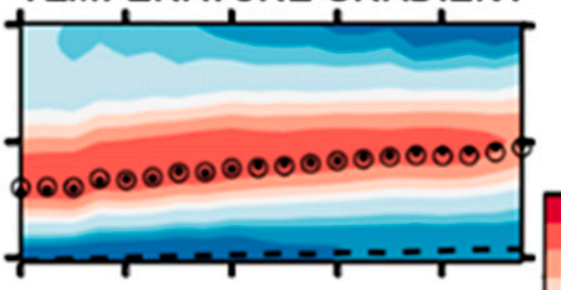

1

TROPOPAUSE HEIGHT

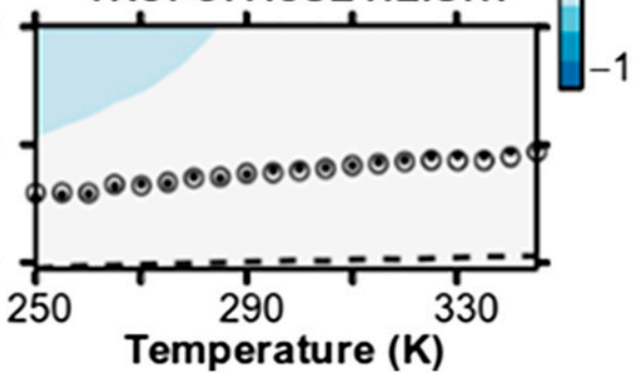

FIG. 7. MAPE variations decomposed into components-temperature gradient, stability, and tropopause height-for simulations in which the mean radiative-equilibrium temperature is varied. In these simulations, the convective stability is the same globally: (a) $\gamma=0.7$ and (b) $\gamma=1.0$. Variations of the latitude of maximum MAPE, indicative of the storm-track latitude, are primarily determined by variations of the latitude of maximum nearsurface temperature gradients. This implies that explaining shifts in near-surface meridional temperature gradients can explain the storm-track shifts seen in these simulations.

simulated climate but a geometric mean of several climates.

Figure 7 shows the response of MAPE and each of its components to variations in mean radiative-equilibrium temperature. Figure $7 \mathrm{a}$ shows the decomposition for simulations that are convectively relatively stable globally $(\gamma=0.7)$, and Fig. 7b shows it for the convectively near-neutral simulations $(\gamma=1.0)$. Figure $8 \mathrm{a}$, on the other hand, shows the MAPE decomposition for simulations in which the mean radiative-equilibrium temperature is varied and the convective static stability in the extratropics $\left(\gamma_{x}=0.7\right)$ is greater than in the deep tropics $\left(\gamma_{e}=1.0\right)$. Figure $8 \mathrm{~b}$ shows the complementary simulations with $\gamma_{x}=1.0$ and $\gamma_{e}=0.7$. By construction, the sum of the latter three diagrams in each panel yields the first diagram. From the figures, it is apparent that the extratropical latitude of maximum MAPE is largely determined by the latitude of 
a
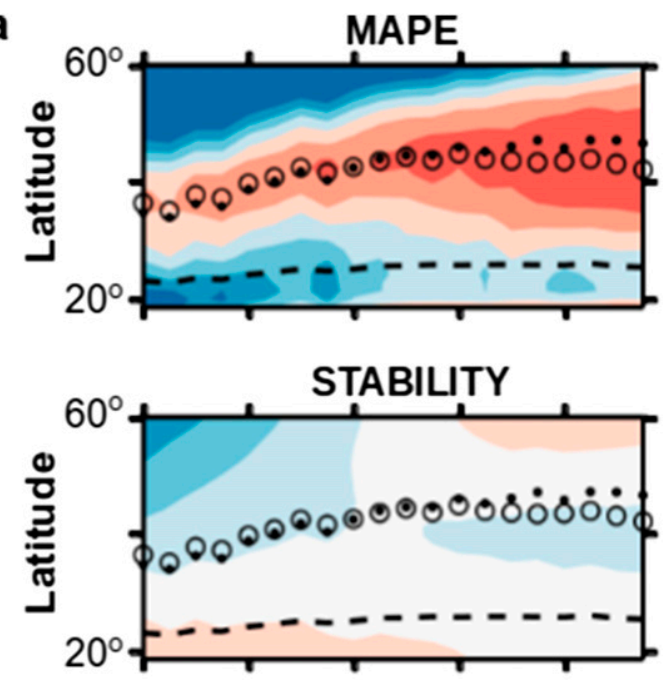

b

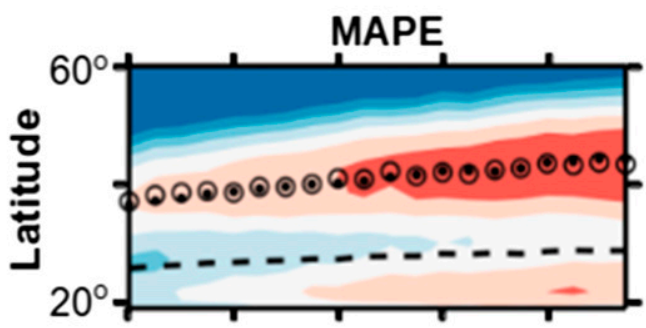

\section{STABILITY}

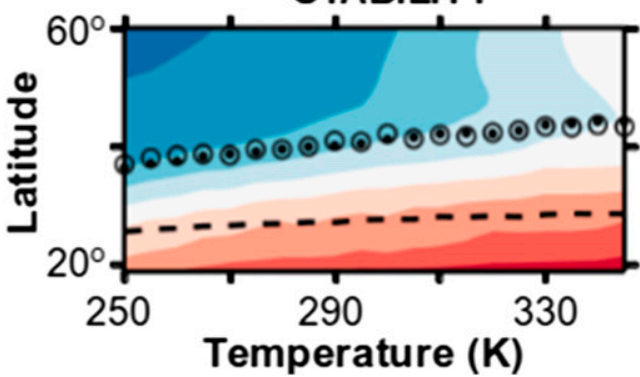

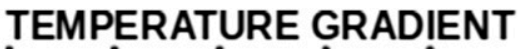
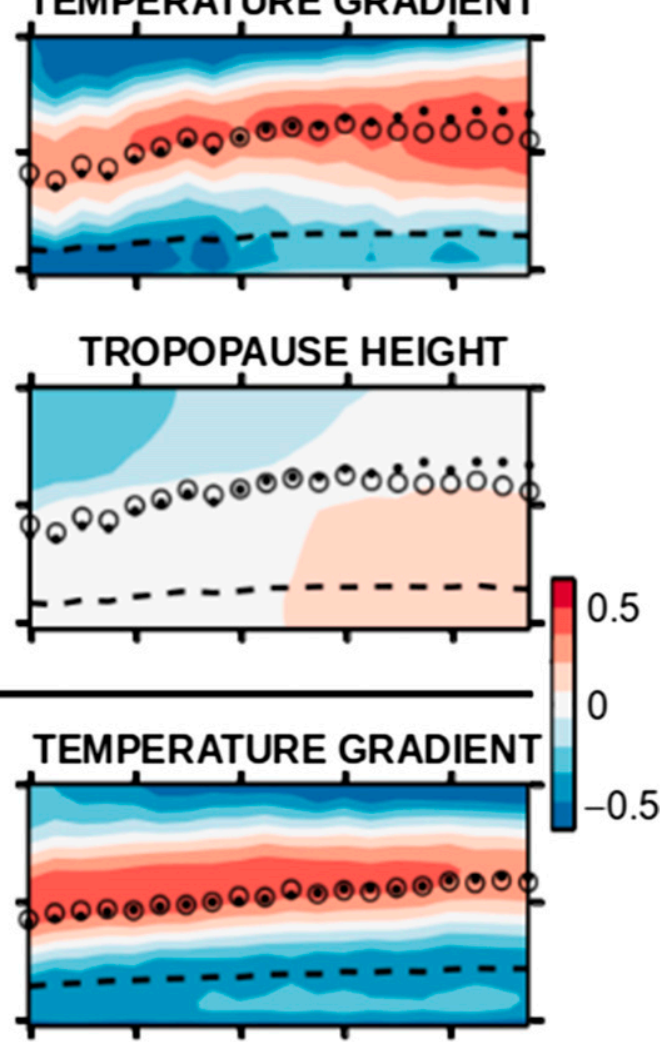

TROPOPAUSE HEIGHT

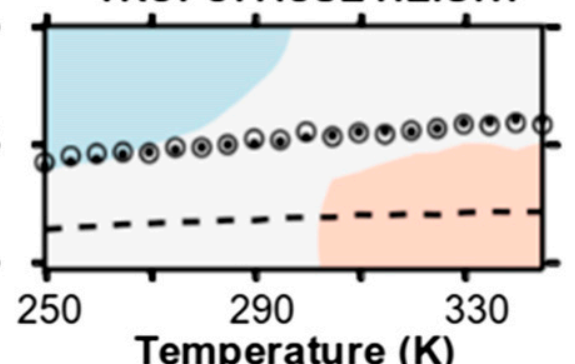

FIG. 8. As in Fig. 7, but for MAPE variations decomposed into components for simulations in which the mean radiative-equilibrium temperature is varied: (a) $\gamma_{x}=0.7$ and $\gamma_{e}=1.0$; (b) $\gamma_{x}=1.0$ and $\gamma_{e}=0.7$.

maximum near-surface meridional temperature gradients, although the meridional structure of MAPE may not necessarily be well captured by the structure of the temperature gradients alone.

Changes in local MAPE with climate primarily result from an interplay between near-surface meridional temperature gradients and near-surface static stability. Maximum midlatitude temperature gradients generally decrease with increasing mean radiative-equilibrium temperature. The near-surface pole-equator temperature contrast in the statistically steady states (as opposed to that in radiative equilibrium, which is fixed in these simulations) also generally decreases with increasing mean radiative-equilibrium temperature; that is, there is polar amplification of warming even in these dry simulations. The reason is the increase in the height of the tropopause with increasing mean temperature (e.g., Schneider 2007), which increases MAPE accessible to midlatitude eddies through the increasing pressure depth of the troposphere $\Delta p$. This in turn strengthens meridional energy fluxes and reduces meridional temperature gradients (Schneider and Walker 2008), leading to a reduced extratropical static stability because the supercriticality, a measure of the slope of isentropes, remains approximately invariant (Schneider and Walker 2006). Changes in MAPE are the net result of such 
a

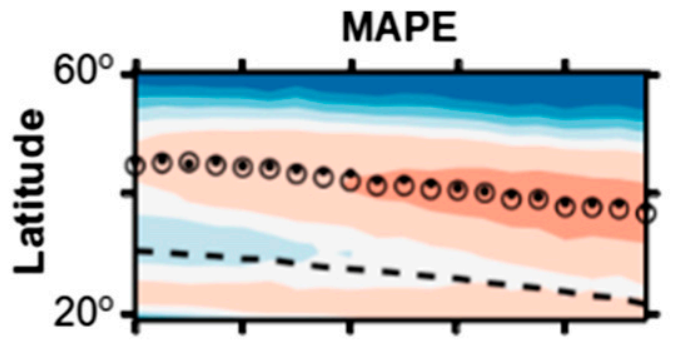

STABILITY

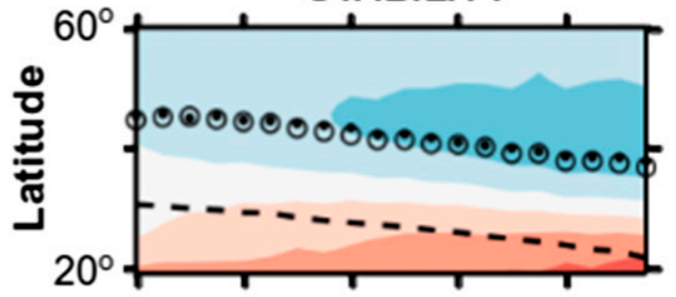

TEMPERATURE GRADIENT

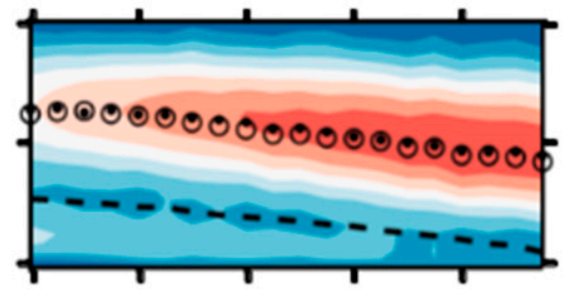

TROPOPAUSE HEIGHT

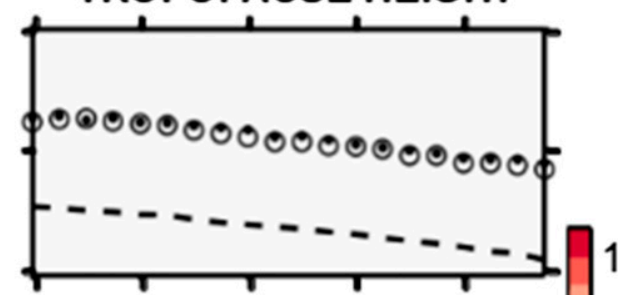

TEMPERATURE GRADIENT

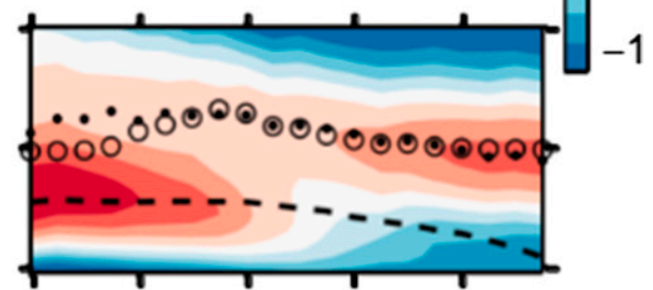

TROPOPAUSE HEIGHT

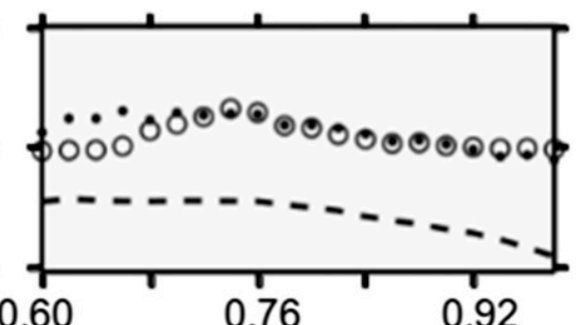

Convective parameter, $\boldsymbol{\gamma}$

FIG. 9. As in Fig. 7, but for MAPE variations decomposed into components for simulations in which the convective static stability is varied (a) in the deep tropics and (b) globally. Variations of the near-surface meridional temperature gradient maximum dominate variations of the MAPE maximum.

partially compensating changes in meridional temperature gradients, static stability, and tropopause height.

Exceptions to the generally decreasing near-surface temperature gradients with warming are seen in the simulations with convectively more stable extratropics than tropics (Fig. 8a). In these simulations, increased extratropical stability implies a decrease in the MAPE accessible to eddies to help diffuse meridional temperature gradients. Furthermore, the radiative-equilibrium forcing relaxes the atmosphere to a profile with increasing meridional temperature gradients as the climate warms. It is likely that these eddies are not efficient enough to dissipate all of the increase in meridional temperature gradients, thus leading to a buildup in the warmer climates.

Figure 9 decomposes MAPE for simulations in which the convective static stability is varied in the deep tropics $\left(\gamma_{e}\right.$; Fig. 9a) and globally $\left(\gamma_{e}=\gamma_{x} ;\right.$ Fig. 9b). It is clear that in these simulations, midlatitude maxima of nearsurface temperature gradients continue to be collocated with the storm tracks. Moreover, near-surface meridional temperature gradients capture both the 
meridional structure and maxima of MAPE. In this case, unlike in the simulations in which mean radiativeequilibrium temperatures are varied, variations in nearsurface meridional temperature gradients can be used as a proxy for MAPE variations.

The bifurcation of the jets (separation of a merged zonal-mean jet stream into a distinct eddy driven and subtropical jet) and increasing strength of the subtropical jet is clearly recognizable in the temperature gradient changes in Fig. 9b. In this set of simulations, where we vary the convective static stability globally, the rate of change of the tropical static stability outpaces the rate of change of mid- and high-latitude static stability. The Hadley circulation expands strongly, while changes in the tropopause height have a negligible direct impact on MAPE.

Although the near-surface meridional temperature gradient does not always reproduce the sense of the rate of change of MAPE with changing climate, it can be used to identify the latitude of maximum MAPE. This cannot be done with the near-surface static stability in these sets of simulations, which is a significant find. Thus, the latitude of the storm tracks is largely determined by the latitude of maximum near-surface temperature gradients. This implies that understanding shifts in nearsurface meridional temperature gradients can go a long way in helping to understand shifts in storm tracks.

\section{b. MAPE reconstructions}

To isolate the role of each component of MAPE on the latitude of maximum MAPE and hence on storm tracks, we reconstruct this latitude using variations with climate of one component contributing to MAPE at a time, while the other two are held fixed to a reference value. Then, we compute the maximum reconstructed MAPE and compare it to the full one. For example, MAPE reconstructed using variations in the tropopause height is given by

$$
\begin{aligned}
\ln \left(\frac{\mathrm{MAPE}}{\overline{\mathrm{MAPE}}^{*}}\right)= & \ln \left(\frac{\Delta p}{\overline{\Delta p}^{*}}\right)+\left[\ln \frac{\left(\partial_{y} \bar{\theta}_{s}\right)^{2}}{{\overline{\left(y_{y} \bar{\theta}_{s}\right)^{2}}}^{*}}\right]_{\mathrm{ref}} \\
& +\left[\ln \frac{\overline{\left(\partial_{p} \bar{\theta}\right)_{s}}}{\left(\partial_{p} \bar{\theta}\right)_{s}}\right]_{\mathrm{ref}},
\end{aligned}
$$

where ref denotes a reference climate. We compare the reconstructed MAPE maxima to the actual MAPE maxima as the climate changes. The reconstructed track of MAPE maxima that most closely matches the original one reflects the component that exerts the most influence on the changing position of storm tracks. Note that, in general, the component reconstructions do not add up to the original MAPE because the component maxima are not always collocated and because of the presence of nonlinear effects.

Figure 10 shows the changes in latitude of maximum reconstructed MAPE for simulations in which mean radiative-equilibrium temperature (Fig. 10a) and the convective static stability (Fig. 10b) are varied. Immediately clear from the figures is that most of the variability of the storm-track shifts comes from variability in near-surface meridional temperature gradients. In the simulations with a globally stable convective static stability $(\gamma=0.7)$, MAPE reconstructed using static stability overshoots the full MAPE, while MAPE reconstructed using the near-surface meridional temperature gradient undershoots. Since the undershoot is greater in absolute value, we conclude that the shift in MAPE with climate here is dominated by shifts in the near-surface static stability. In all other series of simulations, shifts in the near-surface meridional temperature gradients dominate the shifts in the MAPE maximum and thus in the midlatitude storm tracks. The tropopause height exerts little direct control on stormtrack latitude in all but the convectively near-neutral simulations (Fig. 10a, bottom right). Here, both changes in tropopause height and in near-surface meridional temperature gradients accurately reproduce the stormtrack response. The overall dominance of near-surface meridional temperature gradients along the storm tracks is demonstrated in the simulations in which the convective static stability is varied. When varying the convective static stability in the deep tropics $\left(\gamma_{e}\right)$, the static stability starts to influence the storm-track position directly in a small subset of convectively relatively stable climates (Fig. 10b). But for simulations with lower convective static stability in the deep tropics, or when the convective static stability is varied globally, the effect of the convective static stability variations on the storm-track position occurs primarily through changes in extratropical meridional temperature gradients.

It is interesting, and indeed surprising, that even when the convective static stability is varied, and even when it is varied only in the deep tropics, it is the near-surface meridional temperature gradients that dominate shifts in MAPE and in storm-track position. This suggests that changes in the static stability in the deep tropics must be communicated to the extratropical storm tracks through a mechanism that can shift near-surface meridional temperature gradients. Therefore, one avenue for gaining some understanding about storm shifts is to explain how deep tropical static stability changes can influence the midlatitude near-surface temperature gradients, presumably through changes in the Hadley circulation and 
a
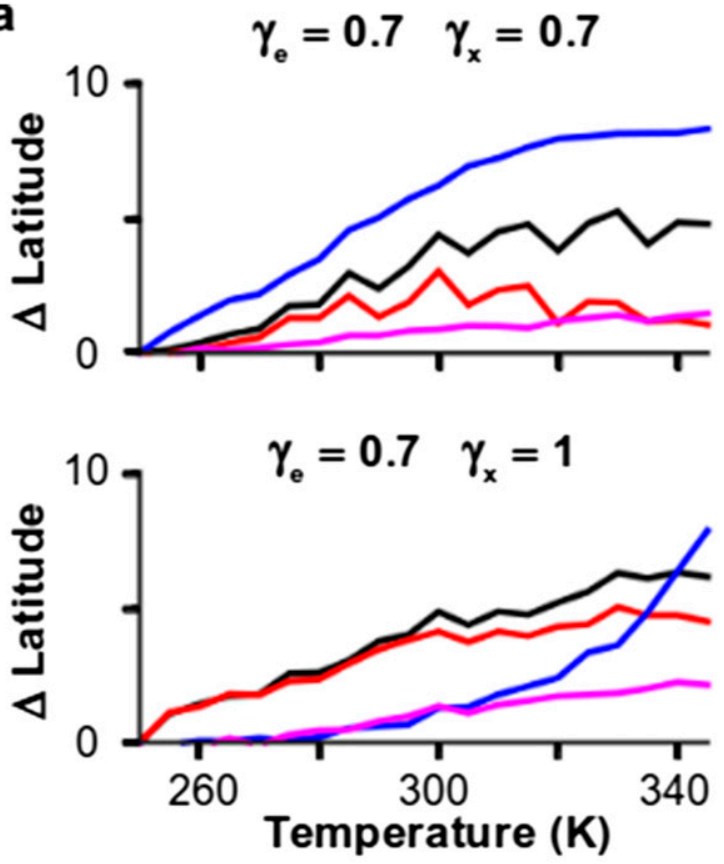

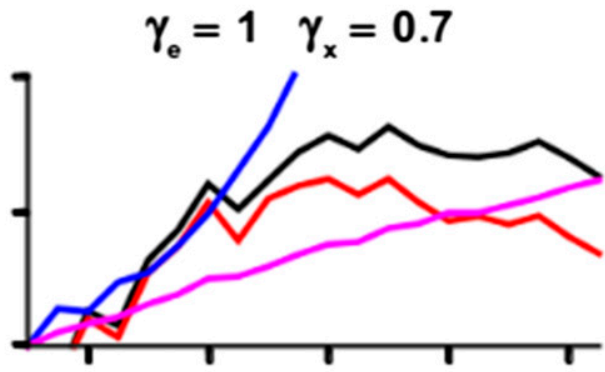

$\gamma_{e}=1 \quad \gamma_{x}=1$

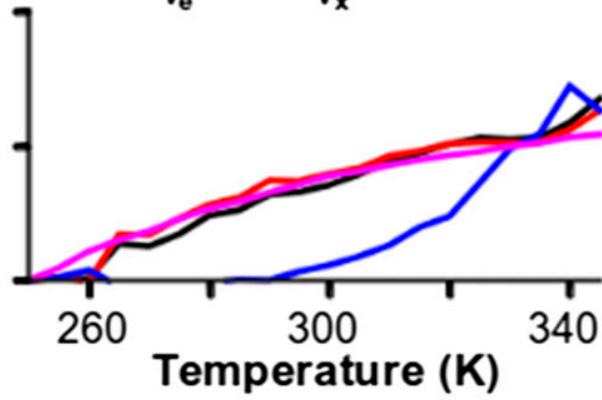

MAPE

\section{TEMP GRAD}

STABILITY

b

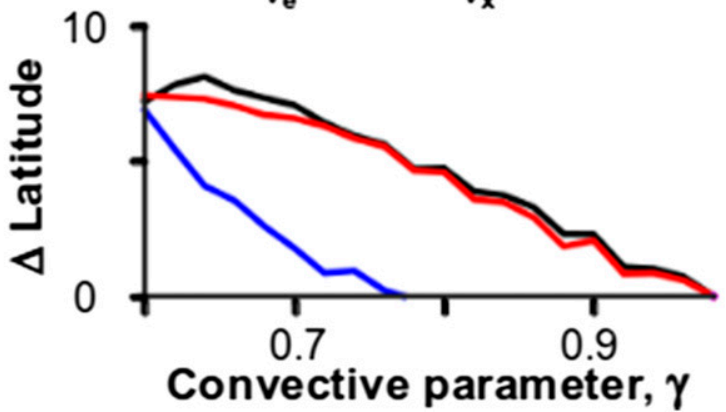

$\gamma=\gamma_{\mathrm{e}}=\gamma_{\mathrm{x}}=$ var

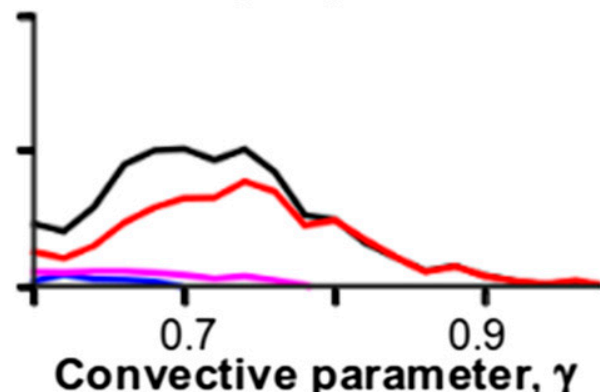

FIG. 10. Evolution of latitude of maximum reconstructed MAPE (i.e., the storm-track latitude) with climate (a) for simulations in which the mean radiative-equilibrium temperature is varied and (b) for simulations in which the convective static stability is varied. In (a), (top left) $\gamma_{e}=\gamma_{x}=0.7$, (top right) $\gamma_{e}=1.0$ and $\gamma_{x}=0.7$, (bottom left) $\gamma_{e}=0.7$ and $\gamma_{x}=1.0$, and (bottom right) $\gamma_{e}=\gamma_{x}=1.0$. In (b), (left) $\gamma_{e}=$ var and $\gamma_{x}=1.0$ and (right) $\gamma=\gamma_{e}=\gamma_{x}=$ var. Each line represents the MAPE maximum reconstructed when the indicated component varies but the other two are held fixed to reference values, taken from the climate with a mean radiative-equilibrium temperature of (a) $295 \mathrm{~K}$ or (b) $\gamma=0.78$. For clarity, latitudes are given as deviations from the latitude of the MAPE maximum in the climate that is (a) the coldest or (b) the least stable. Generally, MAPE reconstructed with near-surface meridional temperature-gradient variations (red line), using reference values for static stability and tropopause height, leads to the best reconstruction of storm-track shifts (black line).

its width. We will illustrate how this can be accomplished in a follow-up publication (Mbengue 2015).

\section{Conclusions}

The position of midlatitude storm tracks responds to a variety of perturbations in the climate system, many of which can already be illustrated in the idealized framework of a dry and statistically axisymmetric climate. One robust response is the poleward shift of storm tracks under global warming, which can already be seen in this idealized framework. Since a generally accepted theory of how storm tracks shift as the climate changes remains elusive, our analysis of dry idealized 
GCM simulations aids the development of such a theory. The idealized dry framework allowed us to isolate quantities that drive storm-track shifts by varying them independently.

Storm tracks generally shift poleward when either the mean temperature increases or when the convective static stability increases-changes in climate parameters that can be decoupled in our dry idealized framework but that usually are coupled in a moist climate. Interestingly, an increase in the convective static stability only in the deep tropics suffices to drive a poleward shift of storm tracks (MS13). Often, but not always, the storm tracks shift poleward in tandem with the terminus of the Hadley circulation, as also seen in other studies (e.g., Kang and Polvani 2011; Ceppi and Hartmann 2013).

We showed that in the dry idealized GCM simulations, storm tracks can be related to MAPE, a general measure of baroclinicity: storm tracks are generally located near the midlatitude MAPE maximum, and EKE in storm tracks generally scales with the local MAPE in the storm tracks. This allowed us to identify factors that lead to shifts in the MAPE maximum and thus in storm tracks. The important finding here is that in most cases, changes in the near-surface meridional temperature gradient are primarily responsible for shifts in the MAPE maximum; changes in extratropical static stability and tropopause height are secondary or act indirectly through affecting near-surface meridional temperature gradients. This is true even in simulations in which only the convective stability in the deep tropics is varied. These results strongly suggest that storm-track shifts in such situations are mediated by changes in the Hadley circulation: As the tropical static stability increases, the Hadley circulation expands (Schneider 2004; Korty and Schneider 2008; Levine and Schneider 2015), pushing larger meridional temperature gradients, and with them the storm tracks, farther poleward. Increases in mean temperatures can similarly act through changes in the Hadley circulation. They lead to an increase of the tropopause height and bulk stability and, through them, likewise lead to an expansion of the Hadley circulation.

What remains is to link changes in MAPE more mechanistically to changes in potential vorticity fluxes and wave-mean-flow interactions and to link Hadley circulation changes to changes in MAPE and, especially, temperature gradients. A quantitative model that demonstrates how such a link between the Hadley circulation and MAPE can arise will be presented in a forthcoming paper (Mbengue 2015). Two modes of storm-track shifts emerge from that model: changes in the width of the Hadley circulation and in the temperature gradients at the terminus of the Hadley circulation can both affect where the maximum extratropical temperature gradients occur, which the results of the present paper have linked to the storm-track position.

Acknowledgments. We are grateful for the financial support provided by the National Science Foundation (Grant AGS-1019211).

\section{APPENDIX}

\section{Hadley Cell Terminus and Storm-Track Latitude}

The streamfunction can be derived from the mass conservation equation in the meridional-pressure plane,

$$
\psi(\phi, p)=\frac{2 \pi a \cos \phi}{g} \int_{0}^{p} \bar{v} d p^{\prime}
$$

where $a$ is Earth's radius. The Hadley cell terminus is determined by first diagnosing the isobar where the Eulerian mass streamfunction (A1) attains its maximum value nearest to the equator. This is usually in the midtroposphere, near $500 \mathrm{hPa}$. Then, the latitude along this isobar where the streamfunction first changes sign poleward of this maximum is used as the Hadley cell terminus.

Finally, the maximum latitude of any field $A(\phi)$ (e.g., EKE for storm tracks) is computed using

$$
\phi_{\max }=\frac{\int_{\phi_{2}}^{\phi_{1}} A^{n} \phi d \phi}{\int_{\phi_{2}}^{\phi_{1}} A^{n} d \phi},
$$

with $n=16$. That is, we approximate the infinity moment (maximum) by the sixteenth moment to obtain an approximation that is less influenced by discretization artifacts.

\section{REFERENCES}

Adam, O., T. Schneider, and N. Harnik, 2014: Role of changes in mean temperatures versus temperature gradients in the recent widening of the Hadley circulation. J. Climate, 27, 7450-7461, doi:10.1175/JCLI-D-14-00140.1.

Ait-Chaalal, F., and T. Schneider, 2015: Why eddy momentum fluxes are concentrated in the upper troposphere. J. Atmos. Sci., 72, 1585-1604, doi:10.1175/JAS-D-14-0243.1.

Barnes, E., and L. M. Polvani, 2013: Response of the midlatitude jets, and of their variability, to increased greenhouse gases in the CMIP5 models. J. Climate, 26, 7117-7135, doi:10.1175/ JCLI-D-12-00536.1.

Bender, F. A.-M., V. Ramanathan, and G. Tselioudis, 2012: Changes in extratropical storm track cloudiness 1983-2008: Observational support for a poleward shift. Climate Dyn., 38, 2037-2053, doi:10.1007/s00382-011-1065-6. 
Bengtsson, L., K. Hodges, and E. Roeckner, 2006: Storm tracks and climate change. J. Climate, 19, 3518-3543, doi:10.1175/ JCLI3815.1.

Blackmon, M., 1976: A climatological spectral study of the $500 \mathrm{mb}$ geopotential height of the Northern Hemisphere. J. Atmos. Sci., 33, 1607-1623, doi:10.1175/1520-0469(1976)033<1607: ACSSOT $>2.0 . \mathrm{CO} ; 2$.

_ J. Wallace, N. Lau, and S. Mullen, 1977: An observational study of the Northern Hemisphere wintertime circulation. J. Atmos. Sci., 34, 1040-1053, doi:10.1175/1520-0469(1977)034<1040: AOSOTN $>2.0 . \mathrm{CO} ; 2$.

Butler, A. H., D. W. J. Thompson, and R. Heikes, 2010: The steadystate atmospheric circulation response to climate change-like thermal forcings in a simple general circulation model. J. Climate, 23, 3474-3496, doi:10.1175/2010JCLI3228.1.

_,- _ and T. Birner, 2011: Isentropic slopes, downgradient eddy fluxes, and the extratropical atmospheric circulation response to tropical tropospheric heating. J. Atmos. Sci., 68 , 2292-2305, doi:10.1175/JAS-D-10-05025.1.

Ceppi, P., and D. L. Hartmann, 2013: On the speed of the eddydriven jet and the width of the Hadley cell in the Southern Hemisphere. J. Climate, 26, 3450-3465, doi:10.1175/ JCLI-D-12-00414.1.

Chang, E. K. M., 2013: CMIP5 projection of significant reduction in extratropical cyclone activity over North America. J. Climate, 26, 9903-9922, doi:10.1175/JCLI-D-13-00209.1.

_ S. Lee, and K. L. Swanson, 2002: Storm track dynamics. J. Climate, 15, 2163-2183, doi:10.1175/1520-0442(2002)015<02163: STD $>2.0 . \mathrm{CO} ; 2$

—, Y. Guo, X. Xia, and M. Zheng, 2013: Storm-track activity in IPCC AR4/CMIP3 model simulations. J. Climate, 26, 246-260, doi:10.1175/JCLI-D-11-00707.1.

Charney, J. G., 1947: The dynamics of long waves in a baroclinic westerly current. J. Meteor., 4, 136-162, doi:10.1175/ 1520-0469(1947)004<0136:TDOLWI >2.0.CO;2.

Chen, G., and I. M. Held, 2007: Phase speed spectra and the recent poleward shift of Southern Hemisphere surface westerlies. Geophys. Res. Lett., 34, L21805, doi:10.1029/2007GL031200.

_, J. Lu, and D. Frierson, 2008: Phase speed spectra and the latitude of surface westerlies: Interannual variability and global warming trend. J. Climate, 21, 5942-5959, doi:10.1175/ 2008JCLI2306.1.

Dutton, J. A., and D. R. Johnson, 1967: The theory of available potential energy and a variational approach to atmospheric energetics. Advances in Geophysics, Vol. 12, Academic Press, 333-436, doi:10.1016/S0065-2687(08)60379-9.

Eady, E. T., 1949: Long waves and cyclone waves. Tellus, 1, 33-52, doi:10.1111/j.2153-3490.1949.tb01265.x.

Emanuel, K., 2007: Quasi-equilibrium dynamics of the tropical atmosphere. The Global Circulation of the Atmosphere, T. Schneider and A. Sobel, Eds., Princeton University Press, 186-218.

Fyfe, J., 2003: Extratropical Southern Hemisphere cyclones: Harbingers of climate change? J. Climate, 16, 2802-2805, doi:10.1175/1520-0442(2003)016<2802:ESHCHO > 2.0.CO;2.

Geng, Q., and M. Sugi, 2003: Possible change of extratropical cyclone activity due to enhanced greenhouse gases and sulfate aerosolsStudy with a high resolution AGCM. J. Climate, 16, 2262-2274, doi:10.1175/1520-0442(2003)16<2262:PCOECA > 2.0.CO;2.

Held, I. M., and T. Schneider, 1999: The surface branch of the zonally averaged mass transport circulation in the troposphere. J. Atmos. Sci., 56, 1688-1697, doi:10.1175/1520-0469(1999)056<1688: TSBOTZ>2.0.CO;2.
Hoskins, B. J., and P. J. Valdes, 1990: On the existence of storm-tracks. J. Atmos. Sci., 47, 1854-1864, doi:10.1175/ 1520-0469(1990)047<1854:OTEOST>2.0.CO;2.

— , and K. I. Hodges, 2002: New perspectives on the Northern Hemisphere winter storm tracks. J. Atmos. Sci., 59, 1041-1061, doi:10.1175/1520-0469(2002)059<1041:NPOTNH > 2.0.CO;2.

$\mathrm{Hu}, \mathrm{Y}$., and Q. Fu, 2007: Observed poleward expansion of the Hadley circulation since 1979. Atmos. Chem. Phys., 7, 52295236, doi:10.5194/acp-7-5229-2007.

Johnson, D. R., 1970: The available potential energy of storms. J. Atmos. Sci., 27, 727-741, doi:10.1175/1520-0469(1970)027<0727: TAPEOS $>2.0 . \mathrm{CO} ; 2$.

Kang, S., and L. M. Polvani, 2011: The interannual relationship between the latitude of the eddy-driven jet and the edge of the Hadley cell. J. Climate, 24, 563-568, doi:10.1175/ 2010JCLI4077.1.

Kidston, J., S. M. Dean, J. A. Renwick, and G. K. Vallis, 2010: A robust increase in the eddy length scale in the simulation of future climates. Geophys. Res. Lett., 37, L03806, doi:10.1029/ 2009 GL041615.

Korty, R. L., and T. Schneider, 2008: Extent of Hadley circulations in dry atmospheres. Geophys. Res. Lett., 35, L23803, doi:10.1029/2008GL035847.

Kucharski, F., 1997: On the concept of exergy and available potential energy. Quart. J. Roy. Meteor. Soc., 123, 2141-2156, doi:10.1002/qj.49712354317.

_ , and A. J. Thorpe, 2000: Local energetics of an idealized baroclinic wave using extended exergy. J. Atmos. Sci., 57, 3272-3248, doi:10.1175/1520-0469(2000)057<3272: LEOAIB $>2.0 . \mathrm{CO} ; 2$.

Kushner, P. J., and L. M. Polvani, 2004: Stratosphere-troposphere coupling in a relatively simple AGCM: The role of eddies. J. Climate, 17, 629-639, doi:10.1175/1520-0442(2004)017<0629: SCIARS $>2.0 . \mathrm{CO} ; 2$

Levine, X. J., and T. Schneider, 2015: Baroclinic eddies and the extent of the Hadley circulation: An idealized GCM study. J. Atmos. Sci., 72, 2744-2761, doi:10.1175/JAS-D-14-0152.1.

Lindzen, R., and B. Farrel, 1980: A simple approximate result for the maximum growth rate of baroclinic instabilities. J. Atmos. Sci., 37, 1648-1654, doi:10.1175/1520-0469(1980)037<1648: ASARFT $>2.0 . \mathrm{CO} ; 2$

Lorenz, D. J., 2014: Understanding midlatitude jet variability and change using Rossby wave chromatography: Poleward-shifted jets in response to external forcing. J. Atmos. Sci., 71, 23702389, doi:10.1175/JAS-D-13-0200.1.

— wind response to global warming in the IPCC scenario integrations. J. Geophys. Res., 112, D10119, doi:10.1029/ 2006JD008087.

Lorenz, E., 1955: Available potential energy and the maintenance of the general circulation. Tellus, 7, 157-167, doi:10.1111/ j.2153-3490.1955.tb01148.x.

Lu, J., A. Vecchi, and T. Reichler, 2007: Expansion of the Hadley cell under global warming. Geophys. Res. Lett., 34, L06805, doi:10.1029/2006GL028443.

, G. Chen, and D. Frierson, 2010: The position of the midlatitude storm track and eddy-driven westerlies in aquaplanet AGCMs. J. Atmos. Sci., 67, 3984-4000, doi:10.1175/ 2010JAS3477.1.

Mbengue, C. O., 2015: Storm track response to perturbations in climate. Ph.D. dissertation, California Institute of Technology, $158 \mathrm{pp}$. [Available online at http://resolver.caltech.edu/ CaltechTHESIS:05112015-075223217.] 
and T. Schneider, 2013: Storm track shifts under climate change: What can be learned from large-scale dry dynamics. J. Climate, 26, 9923-9930, doi:10.1175/JCLI-D-13-00404.1.

Murray, R. J., and I. Simmonds, 1991: A numerical scheme for tracking cyclone centers from digital data part I: Development and operation of the scheme. Aust. Meteor. Mag., 39, 155-166.

O'Gorman, P. A., 2010: Understanding the varied response of the extratropical storm tracks to climate change. Proc. Natl. Acad. Sci. USA, 107, 19176-19180, doi:10.1073/pnas.1011547107.

- 2011: The effective static stability experienced by eddies in a moist atmosphere. J. Atmos. Sci., 68, 75-90, doi:10.1175/ 2010JAS3537.1.

— , and T. Schneider, 2008a: The hydrological cycle over a wide range of climates simulated with an idealized GCM. J. Climate, 21, 3815-3832, doi:10.1175/2007JCLI2065.1.

_ , and $\_$, 2008b: Weather-layer dynamics of baroclinic eddies and multiple jets in an idealized general circulation model. J. Atmos. Sci., 65, 524-535, doi:10.1175/ 2007JAS2280.1.

Orlanski, I., and J. Katzfey, 1991: The life cycle of a cyclone wave in the Southern Hemisphere. Part I: Eddy energy budget. J. Atmos. Sci., 48, 1972-1998, doi:10.1175/1520-0469(1991)048<1972: TLCOAC $>2.0 . \mathrm{CO} ; 2$.

Papritz, L., and T. Spengler, 2015: Analysis of the slope of isentropic surfaces and its tendencies over the North Atlantic. Quart. J. Roy. Meteor. Soc., 141, 3226-3238, doi:10.1002/qj.2605.

Phillips, N. A., 1956: The general circulation of the atmosphere: A numerical experiment. Quart. J. Roy. Meteor. Soc., 82, 123164, doi:10.1002/qj.49708235202.

Riviere, G., 2011: A dynamical interpretation of the poleward shift of the jet streams in global warming scenarios. J. Atmos. Sci., 68, 1253-1272, doi:10.1175/2011JAS3641.1.

Santer, B. D., and Coauthors, 2003: Behavior of tropopause height and atmospheric temperature in models, reanalyses, and observations: Decadal changes. J. Geophys. Res., 108, 4002, doi:10.1029/2002JD002258.

Schneider, E. K., 1984: Some minimization calculations concerning the effect of horizontal eddy momentum fluxes on the equilibrium zonal mean motions. J. Atmos. Sci., 41, 1640-1647, doi:10.1175/1520-0469(1984)041<1640:SMCCTE > 2.0.CO;2.

Schneider, T., 2004: The tropopause and the thermal stratification in the extratropics of a dry atmosphere. J. Atmos. Sci., 61, 1317-1340, doi:10.1175/1520-0469(2004)061<1317: TTATTS $>2.0 . \mathrm{CO} ; 2$.

- 2007: The thermal stratification of the extratropical troposphere. The Global Circulation of the Atmosphere, T. Schneider and A. Sobel, Eds., Princeton University Press, 47-77.

— , and C. Walker, 2006: Self-organization of atmospheric macroturbulence into critical states of weak nonlinear eddy-eddy interactions. J. Atmos. Sci., 63, 1569-1586, doi:10.1175/ JAS3699.1.

, and P. O'Gorman, 2008: Moist convection and the thermal stratification of the extratropical troposphere. J. Atmos. Sci., 65, 3571-3583, doi:10.1175/2008JAS2652.1.

_ macroturbulence in dry atmospheres. J. Atmos. Sci., 65, 21532173, doi:10.1175/2007JAS2616.1.

_ P. A. O'Gorman, and X. J. Levine, 2010: Water vapor and the dynamics of climate changes. Rev. Geophys., 48, RG3001, doi:10.1029/2009RG000302.
Seager, R., N. Harnik, Y. Kushnir, W. Robinson, and J. Miller, 2003: Mechanisms of hemispherically symmetric climate variability. J. Climate, 16, 2960-2978, doi:10.1175/1520-0442(2003)016<2960: MOHSCV $>2.0 . \mathrm{CO} ; 2$.

Seidel, D. J., and W. J. Randel, 2007: Recent widening of the tropical belt: Evidence from tropopause observations. J. Geophys. Res., 112, D20113, doi:10.1029/2007JD008861.

_ Q. Fu, W. J. Randel, and T. J. Reichler, 2008: Widening of the tropical belt in a changing climate. Nat. Geosci., 1, 21-24, doi:10.1038/ngeo.2007.38.

Shaw, T., and A. Voigt, 2015: Tug of war on summertime circulation between radiative forcing and sea surface warming. Nat. Geosci., 8, 560-566, doi:10.1038/ngeo2449.

Simpson, I. R., T. A. Shaw, and R. Seager, 2014: A diagnosis of the seasonally and longitudinally varying midlatitude circulation response to global warming. J. Atmos. Sci., 71, 2489-2515, doi:10.1175/JAS-D-13-0325.1.

Smith, P. J., 1969: On the contribution of a limited region to the global energy budget. Tellus, 21, 202-207, doi:10.1111/ j.2153-3490.1969.tb00432.x.

_ , and L. H. Horn, 1969: A computational study of the energetics of a limited region of the atmosphere. Tellus, $\mathbf{2 1}$, 193-200, doi:10.1111/j.2153-3490.1969.tb00431.x.

_ D. G. Vincent, and H. J. Edmon, 1977: The time dependence of reference pressure in limited region available potential energy budget equations. Tellus, 29, 476-480, doi:10.1111/ j.2153-3490.1977.tb00759.x.

Swart, N., and J. Fyfe, 2012: Observed and simulated changes in the Southern Hemisphere surface westerly wind-stress. Geophys. Res. Lett., 39, L16711, doi:10.1029/2012GL052810.

Tailleux, R., 2013: Available potential energy and exergy in stratified fluids. Annu. Rev. Fluid Mech., 45, 35-58, doi:10.1146/ annurev-fluid-011212-140620.

Tandon, N. F., E. P. Gerber, A. H. Sobel, and L. M. Polvani, 2013: Understanding Hadley cell expansion versus contraction: Insights from simplified models and implications for recent observations. J. Climate, 26, 4304-4321, doi:10.1175/ JCLI-D-12-00598.1.

Thompson, D. W. J., and T. Birner, 2012: On the linkages between the tropospheric isentropic slope and eddy fluxes of heat during Northern Hemisphere winter. J. Atmos. Sci., 69, 18111823, doi:10.1175/JAS-D-11-0187.1.

Tsushima, Y., and Coauthors, 2006: The importance of the mixedphase cloud distribution in the control climate for assessing the response of clouds to carbon dioxide increase: A multi-model study. Climate Dyn., 27, 113-126, doi:10.1007/ s00382-006-0127-7.

Walker, C. C., and T. Schneider, 2006: Eddy influences on Hadley circulations: Simulations with an idealized GCM. J. Atmos. Sci., 63, 3333-3350, doi:10.1175/JAS3821.1.

$\mathrm{Xu}, \mathrm{K}$., and K. Emanuel, 1989: Is the tropical atmosphere conditionally unstable? Mon. Wea. Rev., 117, 1471-1479, doi:10.1175/1520-0493(1989)117<1471:ITTACU>2.0.CO;2.

Yin, J. H., 2005: A consistent poleward shift of the storm track in simulations of 21st century climate. Geophys. Res. Lett., 32, L18701, doi:10.1029/2005GL023684.

Yuval, J., and Y. Kaspi, 2016: Eddy activity sensitivity to changes in the vertical structure of baroclinicity. J. Atmos. Sci., 73, 17091726, doi:10.1175/JAS-D-15-0128.1. 